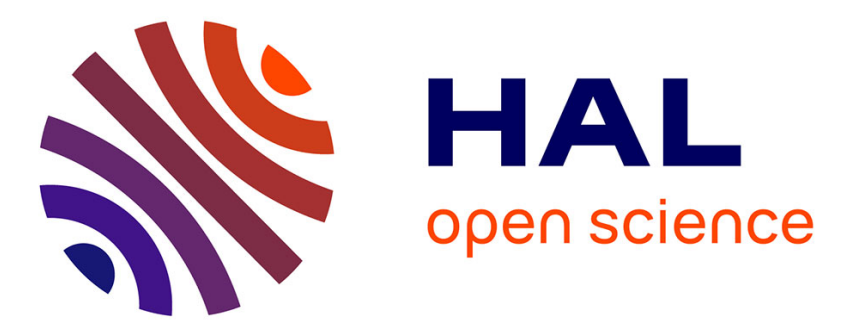

\title{
Non-invasive prenatal testing: A diagnostic innovation shaped by commercial interests and the regulation conundrum
}

Ilana Löwy

\section{- To cite this version:}

Ilana Löwy. Non-invasive prenatal testing: A diagnostic innovation shaped by commercial interests and the regulation conundrum. Social Science and Medicine, 2020, pp.113064. 10.1016/j.socscimed.2020.113064 . hal-03480032

HAL Id: hal-03480032

https://cnrs.hal.science/hal-03480032

Submitted on 20 Jan 2022

HAL is a multi-disciplinary open access archive for the deposit and dissemination of scientific research documents, whether they are published or not. The documents may come from teaching and research institutions in France or abroad, or from public or private research centers.
L'archive ouverte pluridisciplinaire HAL, est destinée au dépôt et à la diffusion de documents scientifiques de niveau recherche, publiés ou non, émanant des établissements d'enseignement et de recherche français ou étrangers, des laboratoires publics ou privés. 
Non-invasive prenatal testing: a diagnostic innovation shaped by commercial interests and the regulation conundrum.

\section{Abstract}

Non-invasive prenatal testing (NIPT) is grounded in the analysis of free circulating fetal DNA (cfDNA) in pregnant women's blood. The rolling out of this screening method was in large part driven by commercial firms, which hoped to reach a huge potential market by offering a test that was expected to be risk-free, reliable, inexpensive, and able to detect a wide range of genetic traits of the future child. To date, most predictions about the scope and uses of NIPT have not materialized: in 2020 NIPT detects only a limited number of genetic anomalies, while results have to be confirmed by amniocentesis. Nevertheless NIPT has become a commercial success. Nevertheless the implementation of NIPT has tended to diverge across different national settings. In countries that already have state-sponsored screening for Down risk, NIPT has been offered by the state health insurance to women defined as "high risk", using a variant of the test that detects only three autosomal aneuploidies: trisomy 21,13 and 18 . These countries effectively regulate the supply of NIPT on grounds of cost-effectiveness and reliability. In countries without state-sponsored screening for Down risk, in contrast, multiple versions of NIPT covering a wider range of birth defects are commonly available on the free market, and purchased by women at low as well as high risk of having an affected child. Market-based healthcare systems tend to present women who can afford to pay for NIPT with a largely unregulated 
choice of technologies - though reimbursement rules imposed by private insurance providers may serve in effect to regulate use by those consumers who cannot afford to pay for tests from their own pockets. This regulatory divergence is shaped by the presence or absence of prior state-sponsored screening programs for Down risk.

Keywords:

pregnancy, fetus, selective abortion, amniocentesis, circulating free fetal DNA, non-invasive prenatal diagnosis, genetic testing, Down syndrome.

$*$

i. Introduction: NIPT—distinct trajectories of a diagnostic innovation.

Noninvasive prenatal testing (NIPT) examines free circulating fetal DNA (cfDNA) in maternal blood in order to identify fetal anomalies. First introduced in 2011, NIPT is now offered by numerous biotechnology companies who compete in a world-wide prenatal testing market. The declared aim of cfDNA-based NIPT, when first introduced, was to provide a reliable and risk-free method of identifying selected genetic anomalies of the fetus, above all the presence of an abnormal number of chromosomes (aneuploidy). In the longer term, it was expected that cfDNA analysis would be expanded to provide a "reading" of the entire fetal genome aimed at identifying a much wider range of genetic conditions and risks (e.g., Benn and Chapman, 2010; Greely, 2011). As of 2020, it is still too early to decide what the future of NIPT will be. Looking back over the first eight years 
of diffusion of this approach (2011-2019), however, alerts us to a development that was scarcely anticipated in the debates that preceded its marketing - namely that the way NIPT has been rolled out in different national settings has tended to diverge, depending, among other things, on whether countries already have state-sponsored screening for Down syndrome risk, or whether NIPT is delivered via market-based healthcare.

In countries with pre-existing, nation-wide structures of screening for Down syndrome risk, NIPT is distributed mainly through national health systems and is limited to a search for three major autosomal aneuploidies: trisomy 21 (Down syndrome), 13 and 18. In these settings, NIPT is usually (as of early 2020) a "second level screen" - proposed only to women previously defined as being at high risk of carrying a trisomic fetus through first level screening using a combination of serum markers and obstetrical ultrasound - and is regulated according to the same criteria (reliability, reproducibility) as those which govern the use of serum markers to test for "Down risk".

This contrasts with the US a devoid of a national health care system, where NIPT is distributed primarily as a consumer item, available on the market, or with Brazil where, since abortion is criminalized, national health system does not include prenatal testing for fetal anomalies. In these countries NIPT can be purchased by high and low risk women, and its users can decide whether they want to know only if the fetus has trisomy 21,13 or 18 , or whether they wish also to receive additional information about other genetic anomalies.

This divergence is far from being absolute. In countries where a national health system confines NIPT to screening for the three major autosomal aneuploidies in high risk women, affluent health care users can often circumvent these restrictions by directly purchasing other cfDNA-based tests. Moreover, the provision of prenatal screening by a 
national health service does not neceserily mean that the majority of pregnant women elect the variant of NIPT it proposes (Metlzer, 2020). Meanwhile in countries where NIPT is distributed mainly through market mechanisms, the choices available to women and couples who cannot afford to pay directly for cfDNA tests may still be restricted by the reimbursement rules operated by their private health insurance providers, who act in effect to regulate the scope of NIPT use.

In any given country, the adoption and use of cfDNA-based tests is thus shaped by the structure of health care, local regulatory framework, legal constraints, cost/efficacy considerations governing health insurance, and, above all by previous approaches to screening for "Down risk." Nevertheless, between 2011 and 2020, the distribution and use of NIPT in each country has generally tended to follow one of two broadly divergent patterns. This paper illustrates these by describing the diffusion of NIPT in the USA on the one hand and in Western European countries on the other. It then highlights how these patterns of diffusion may be affected and modulated by local circumstances by looking first at the situation in Brazil and secondly, and more briefly, at China. The paper concludes by stressing that although NIPT is grounded in shared technology, its adoption is shaped by situated variables.

The view of NIPT presented in this paper is grounded in a mixed methods approach to contemporary history, using a combination of direct observations, collection of testimonies, and a historically-oriented reading of printed sources. The research was undertaken as part of a collective program of comparative investigation of the history and current practices of prenatal diagnostics and testing in Europe and Brazil, which included numerous interviews with key actors (Ville et al., 2013). In this context, the author conducted three years of observation of fetal 
pathology and clinical genetic practices in France and Brazil, including interviews with the clinical specialists (Löwy, 2018). Additional information on China derives from shorter collaboration on local uses of NIPT (Zeng et al. 2016). The present text is primarily based on a reading of the literature relating to the implementation of Down risk screening and NIPT in the different countries, informed by the findings of the project as a whole and selected to illuminate the different ways that NIPY was developed implemented in the different countries. Where interview data are reported in the present text, they are from the author's research with clinicians in Brazil.

\section{ii. Screening for Down risk before NIPT.}

The first prenatal tests for genetic disorders, introduced in the late 1960s, employed invasive technologies to collect fetal cells, either from the amniotic fluid (amniocentesis) or the fetal part of the placenta (chorionic villus sampling (CVS)). The fetal cells could then be tested for the presence of an abnormal number of chromosomes (aneuploidy) or for biochemical markers of a hereditary metabolic disease. Gynecologists and public health experts were especially concerned about the risk of Down syndrome (trisomy 21). Women of "advanced maternal age" were understood to be at higher risk than younger women of giving birth to a Down syndrome child, so were advised to undergo amniocentesis or CVS to determine the fetus's chromosomal status. However, amniocentesis and CVS were also linked with risk of spontaneous abortion of a healthy fetus. In younger women, the risk of losing a pregnancy following an invasive test was seen as higher than the risk of having a 
Down syndrome child. Consequently, physicians did not recommend such tests to women under 35 (Löwy, 2014).

In the early 1970s some experts did propose to offer amniocentesis for Down risk to all pregnant women (Stein et al, 1973), but this was a programmatic statement rather than a realistic suggestion: amniocentesis was too risky and expensive to become a generalized prenatal test. In the 1980s and early 1990s, however, experts discovered that fetuses with increased nuchal translucency (accumulation of liquid behind the fetal neck, visible using ultrasound) at 11-12 weeks of pregnancy were at higher risk of trisomy 21 . They also found that changes in levels of certain biochemical markers in a pregnant woman's serum indicated a higher probability that the fetus had an abnormal number of chromosomes. An algorithm combining data from ultrasound and serum tests, together with a woman's age, was developed to calculated the woman's individual "risk number," that is her odds of carrying a fetus with a chromosomal anomaly. Those with a "risk number" higher than a predetermined value (typically 1 in 150 to 1 in 300 ) were offered the possibility of undergoing an invasive test. The introduction of these preliminary non-invasive tests made it possible to implement screening of all pregnant women for "Down syndrome risk." This in turn favored a rapid extension of prenatal diagnosis, and would become the moving force behind the development of cfDNA-based NIPT (Löwy, 2017).

Screening for Down risk was introduced in several Western European countries where prenatal care is partly or totally covered by national health insurance, but the specific form of such screening and its uptake have been highly variable (Boyd and Game, 2011). Often screening was first offered in the framework of large-scale clinical trials. When these trials showed screening to be effective, it was integrated into national systems of pregnancy care and surveillance. In the US women's decisions about screening for 
Down risk were often affected by advice provided from their healthcare providers and by their access to resources. By consequence fewer women underwent testing for Down risk: experts estimated that fewer than $2 \%$ of pregnant women in the US underwent amniocentesis for this indication, compared to 5-7\% in Western Europe (Greely, 2011). In the absence of organized screening for Down risk, women, especially those from lower socioeconomic strata, thus had fewer opportunities to learn about health problems affecting their future child, and to elect to terminate the pregnancy where that option was available. This was seen as a problem by advocates of screening, and as a blessing in disguise by its opponents (Vassy, 2006).

Important differences in organization of screening for Down among Western European countries stem from differences in local health care cultures and organization of prenatal care (Crombag et al, 2014; Vassy et al, 2014). In France, screening for Down risk was introduced in the early 1990s, and in 2009 the French Health Ministry officially recommended that all women be offered first semester screening for Down. Screening is voluntary, and women have to sign an informed consent form, but refusals to undergo screening are relatively rare (Vassy, 2006; Dommergues et al., 2010). The UK implemented several pioneering programs for first semester screening around 2000; and these were gradually extended in the following years (Williams et al, 2005; Thomas, 2017). Overall uptake of screening for Down syndrome in the UK is lower than in France, as is the (official) number of terminations of pregnancy following a diagnosis of fetal anomaly. However the French and the UK data are not strictly comparable since in the UK women can abort without providing a medical reason until 24 weeks of pregnancy, compared with only 14 weeks in France (Vassy et al. 2014). Denmark has a very high acceptance rate of screening for Down, as does Finland. By contrast, in Norway screening 
for Down is offered only to women over 38 years and those known to have an increased risk of giving birth to a disabled child, and the uptake of screening for Down is relatively low. In Sweden and Iceland women receive detailed information about screening for Down, but are not actively encouraged to undergo it (Schwennesen et al, 2010; Mescus, 2012). In the Netherlands women are not encouraged to screen for Down risk and the test is not covered by the national health insurance, while Belgium adopted a similar screening model to the French one (Crombag et al, 2014; Roseman 2016).

Visibility of the risk of Down syndrome and, by extension, of other fetal chromosomal anomalies is thus a situated entity. It reflects complex interactions between legal, economic, material, sociocultural and professional considerations. Differences in the implementation and diffusion of tests to reveal the presence of fetuses with chromosomal anomalies produce what, following anthropologist Margaret Lock, we might call "local fetal biologies" (Lock, 2001). Meanwhile, debates over the diffusion and regulation of "screening for Down" reflect persistent unease with a diagnostic approach which, although often presented as intended to help parents prepare for the birth of a "special needs" child, in practice often results in a decision to terminate a pregnancy. In this regard, prenatal diagnosis of a genetic condition is radically different from other genetic tests. Where debates over such tests typically include considerations of their clinical utility (Parthasarathy, 2007), the highly emotional tenor of debates over abortion for non-lethal fetal indications, entangled as they are with discussions of disability rights and fears of presumed eugenic aspirations to exterminate imperfect humans, have made it very difficult to establish a single, agreed evaluation of the clinical utility of screening for Down syndrome. 
iii. Marketing of an industry-driven innovation

Industry—especially the pharmaceutical, biotechnology or medical instruments industries—has long been a major driver of biomedical innovation (e.g., Hobby,1985; Blume, 1992, Marks, 2015). This was especially evident in the case of NIPT. Initial efforts to develop approaches to examine fetal hereditary material using cells or free nucleic acids in maternal serum were made in public sector research laboratories. But industry soon came to play a key role in the large-scale testing and validation of this technology.

Scientists first attempted to isolate fetal cells present in the maternal circulation in the late 1970s using the newly developed cell sorter instrument (Herzenberg et al. 1979). The inventor of the cell sorter, Leonard Herzenberg, had a son with Down syndrome, and was especially interested in prenatal diagnosis of this condition (Bianchi, 2010). However, despite partial successes in the research laboratory, scientists failed to develop clinical applications of this method. The breakthrough came with the discovery of significant amounts of circulating free fetal DNA (cfDNA) in the blood of pregnant women by Denis Lo, then at Oxford university, and his collaborators (Lo et al, 1997; Bianchi, 1998; Landau 2012; Romero, 2018). In the 2000s, the increasing power of computers led to the development of a new genomic technology—next generation sequencing—which made possible the development of cfDNA-based tests to detect Down syndrome. In 2008, Denis Lo's group at the Chinese University, Hong Kong and Stephen Quake's group at Stanford university independently patented cfDNA-based tests for Down. Though working in academic institutions and funded by public money, Lo's group was at that point collaborating with the biotechnology firm Sequenom, and Quake's group with the firm 
Verinata, who funded and promoted the large-scale tests of the new technology, with diagnosis of trisomy 21 as their first stated goal (Landau, 2012; Davis, 2013; Agraval et al; 2013; Twiss et al., 2014; Lo, 2015). Marketed as a radical revolution in prenatal diagnosis, the cfDNA-based tests rapidly entered a period of commercial exploitation, patent wars and intense competition for markets. The predictions of high profitability that motivated this competition were quickly fulfilled: in 2018, prenatal tests -which include cfDNA based tests, but also multi-gene panel tests - dominated the market for genetic testing (Evans and Veermeesh, 2016; Philips et al. 2018).

The new technology, first known as non-invasive prenatal diagnosis (NIPD) then non-invasive prenatal testing (NIPT), was initially conceived as a replacement for the existing methods of screening for Down syndrome, particularly serum tests. In 2012 clinical trials validated NIPT's capacity to detect trisomy 21, 13 and 18 (Palomaki et al, 2012), and four cfDNA-based tests-Seqenoms's Materni T21 Plus, Verinata's Verifi, Ariosa's Harmony, and Nantera's Panorama—obtained marketing permission in the US. Initially priced between $\$ 800$ and $\$ 1400$, by 2018 the price-range for NIPT was reported to be $\$ 500-\$ 2100$. This was more expensive than alternative methods of testing for Down risk (Allyse and Wick, 2018)—one of the main reasons why national health systems did not rapidly adopt this technology as a first-tier test. In 2013, tests for abnormal numbers of sex chromosomes and for fetal sex were added to Sequenom's Materni T21 Plus, Verinata's Verify, and Nantera's Panorama (Agrawal et al, 2013). While women could elect to test only for trisomy 21,13 and 18, many women opted for the full range of tests, despite the fact that screening for sex chromosome anomalies has lower predictive value than screening for trisomy 21 (Allyse and Wick, 2018; Ramdanev et al, 2018; Bianchi, 2019). 
Initially NIPT was proposed only to women defined as being at high risk of a chromosomal anomaly. However, NIPT producers were keen to prove that the test was efficient in low-risk women too—a much larger market for their products.

The first studies of the use of NIPT by low-risk women, published in 2014, and funded by the genetic testing company Illumina, supported this view. In half of the "low risk" women who received a positive NIPT result for Down, this result was confirmed by amniocentesis. By contrast, only about $4 \%$ of women classified as being at higher than average risk of carrying a Down syndrome fetus using a combination of serum and ultrasound markers had that result confirmed by amniocentesis (Greene, 2014). This result was not seen as entirely reliable, as the trial enrolled only a relatively small sample of women. Moreover, some experts favored firstlevel screening with a combination of serum and ultrasound markers because it made possible the detection of a wider range of fetal anomalies. Consequently, guidelines issued in 2015 by the American College of Obstetrics and Gynecology (ACOG) did not validate the use of NIPT in low-risk women (ACOG, 2015; Benn et al., 2015).

Despite the lack of official endorsement, however, the use of NIPT as a "first screen" rapidly came to dominate the diffusion of this test in the US. By the end of 2016, several North American professional societies such as the Society for Maternal Fetal Medicine (SMFM), the American Congress of Obstetricians and Gynecologists (ACOG), and the American College of Medical Genetics and Genomics (ACMG) had altered their position to recommend that NIPT can be made available to all pregnant women. This view was also endorsed in 2017 by the Society of Obstetricians and Gynaecologists of Canada (SOGC) and the Canadian College of Medical Genetics (CCMG), though noting that NIPT might not be funded by the public (provincial) health insurance systems (Birko et al., 2018). Data from tests performed by Ariosa company show that 
while in $2014,70 \%$ of the demands originated from women over 35 , the proportion of older women had decreased to $50 \%$ in 2017 (Chen et al, 2018)

One of the consequences of the rapid diffusion of NIPT in the US was that many women who primarily sought reassurance that their fetus did not have Down syndrome, but who accepted the additional tests for sex chromosome aneuploidy (SCA), learned that their fetus had a high probability of an anomaly they might otherwise never have heard about. In some cases this information may have influenced women's decisions about the future of their pregnancy; in others, it might have influenced parents' perception of their child, potentially depriving that child of the opportunity to have a childhood unburdened by parental knowledge of their genetic difference (Howard-Bath et al., 2018; Kornman et al., 2018).The problem of unanticipated findings of NIPT was amplified in 2014 when several companies proposed "extended" NIPT that tested for additional chromosomal anomalies (mostly deletions) linked with other inborn impairments—-some of which, such as DiGeorge syndrome (22q11.2 del), have variable expression (Hayden, 2014). Offered at a somewhat higher price than "basic" NIPT, this "extended" or "complete" NIPT was marketed, like the more basic versions, as a means of preparing parents for the birth of a "special needs" child (Löwy, 2017). Presented as a non-problematic improvement of the existing test, it was criticized nevertheless by some obstetricians, who pointed out to uncertainties produced by the "complete" NIPT (Allyse and Chandrasekhran, 2015; Hashiloni-Dolev et al., 2019; Metzler, 2020).

NIPT is not presented as providing a firm diagnosis of a genetic anomaly; rather, pregnant women are told that the results have to be confirmed by amniocentesis or CVS (Stoll, 2013; Dondorp et al., 2015; Taneja et al., 2016). Not all women accept this principle, however. In the US, $6 \%$ of women whose NIPT results indicate a high 
probability of fetal chromosomal anomaly elected to abort without further verification, while a significant proportion of those diagnosed with a high probability of sex chromosome aneuploidy elected not to perform additional tests (Dar et al, 2014; Ramdanev et al, 2018). In many such cases, it is likely that women decided to terminate a pregnancy on the basis of early NIPT results alone because they preferred not to wait until it was possible to confirm those results with amniocentesis and risk facing a more complicated second-trimester abortion.

The introduction of NIPT followed a very different trajectory in Western European countries which implemented the technology through their national health systems. These countries followed the recommendations set out in a shared position document on the uses of NIPT, issued in 2015 by the European Society of Human Genetics and the American Society of Human Genetics. This document recommended that, for the time being, the use of NIPT be limited to searching for just three autosomal aneuploidies: trisomy 21 (Down syndrome) and trisomy 13 and 18 - these last two conditions being linked with very high rates of prenatal and postnatal mortality. It also recommended that NIPT be offered only to women already defined as being at "high risk" of chromosomal anomalies. Those with positive results of NIPT are then offered an invasive test. This use of NIPT as "secondlevel screen" markedly increases the odds that an invasive test will confirm the presence of a trisomy (Dondorp et al., 2015). In early 2019, the French national health system adopted such use of NIPT, and at the same time increased the threshold definition of "higher than average risk of Down" from 1:250 to 1:1000 (HAS, 2019). The British NHS proposes to gradually do the same, but without modifying its definition of "high risk of Down" from the current level of 1:150. 
The decision not to offer NIPT as a first screen reflects mainly cost/efficacy considerations. While advocates of NIPT as a first screen argued that this approach detects more cases of autosomal trisomy than the combination of serum markers and nuchal translucency (Hashiloni-Dolev et al, 2019), health administrators in several European countries were not persuaded that the small increase in detection rate justifies the higher cost of screening. By contrast, testing for conditions such as sex chromosome anomalies and deletions was rejected because these tests are perceived to be less reliable, leading to a risk of undesirable outcomes and posing difficult ethical dilemmas. While a fall in the cost of NIPT may therefore make it more acceptable as a first screen, it is less likely to lead to the adoption of "extended NIPT" (Birko et al, 2018; Ramdaney et al , 2018; Metzler, 2020).

In countries with pre-existing screening for Down, NIPT is presented as simply a technical improvement of such screening, while the possibility of replacing serum tests for Down risk with the use of NIPT as a first screen for trisomy 21, 13 and 18 is not expected to produce a dramatic shift in pre-existing patterns of prenatal screening. While affluent users in Europe, including "low risk" women, can go private to purchase either a "basic" or an "extended" NIPT test, it seems likely that only a small fraction of women in countries with a national health insurance system will purchase NIPT on the private market. Rather, the introduction of NIPT into countries with national health systems and preexisting Down screening is expected to produce a significant decrease in the number of amniocenteses performed, thus sparing women the pain and stress linked with this invasive test (Chitty and Kroese, 2015; Dondorp et al., 2015; Horn, 2019). It is expected to reduce the number of spontaneous miscarriages due to invasive tests, though a prospective French clinical trial failed to detect such an effect (Malan et al, 2018). The introduction of cfDNA- 
based tests in countries with pre-existing screening for Down has thus produced (for now) only relatively modest changes in prenatal diagnosis rather than the revolution that some predicted (Zeng et al, 2016; Lewis et al, 2017).

iv) Discussing NIPT before and after the marketing of this diagnostic technology.

In 2007, as commercial marketing of cfDNA-based tests looked increasingly imminent, US jurist Carolyn Jacobs Chachkin produced a detailed and thoughtful review of the potential advantages and pitfalls of the new diagnostic technology. Chachkin assumed that cfDNA-based tests would provide a definitive diagnosis of fetal anomalies, and would be much cheaper than existing diagnostic approaches (she estimated that their price would be between $\$ 100$ and $\$ 200$ ). On that basis, Chachkin predicted that these tests would rapidly become integrated into routine prenatal care, dramatically increasing the number of US women who use prenatal genetic testing. Such testing, she anticipated, would rapidly become the standard of care, would be fully covered by insurance companies, and would become as popular as prenatal ultrasound. A probable consequence would be a significant increase in abortions for fetal anomalies and a significant decrease in the proportion of babies born with genetic disorders. The introduction of cfDNA-based diagnosis might therefore increase the pressure to abort impaired fetuses, leading to a subtle form of eugenics. Overall, however, Chachkin viewed the arrival of the new tests as a very positive development (Chachkin, 2007). 
Other US scholars shared Chachkin's assumptions and concerns. They too assumed that the new technology, then coming to be known as noninvasive prenatal diagnosis (NIPD), would rapidly became accurate and inexpensive, and would detect a great number of hereditary or genetic disorders. They viewed large-scale diffusion of commerciallyproduced NIPD as an ineluctable development, and pointed both to its potential advantages (enlargement of parental choice and a probable reduction of prevalence of severe hereditary disorders) and to its possible dangers (overwhelming parents-to-be with confusing and stress-generating information; a push toward abortion for moderate and minor fetal impairments; and greater stigmatization and social exclusion of those living with disabilities) (Benn and Chapman, 2009; Benn and Chapman, 2010; Greely and King, 2010; Greely 2011; Proffitt, 2013). These risks might be amplified by direct-to-consumer (DTC) diffusion of NIPD (Haymon, 2011; De Jong et al, 2011).

UK experts who evaluated NIPD's future were more cautious. They predicted that the new technology would be employed to detect autosomal aneuploidies, but were less certain that it would move rapidly beyond this indication. They were also less sure that NIPD would swiftly replace testing for serum markers of fetal anomalies. Nevertheless, they too assumed that cfDNA-based tests for a wide range of genetic conditions would reach the market in the relatively near future, amplifying the ethical dilemmas associated with selective abortion for fetal indication. Such dilemmas, they added, might be exacerbated by the fact that NIPD was being developed exclusively by private companies and would be commercially marketed (e.g. Hall et al., 2009, Wright, 2009). Discussions about the future of cfDNA-based tests did not invoke "clinical utility" since it is difficult to frame potential prevention of the birth of impaired children in terms of "utility", but they did discuss potential social harms associated with these tests. They also did not explicitly 
debate the possibility of prohibiting specific uses of NIPD, nor of their marketing directly to consumers.

Scholars who participated in the early debates on NIPD in the USA and the UK did not predict that the results of cfDNA-based tests would need to be confirmed by an invasive test, nor did they doubt that the diffusion of tests for selected chromosomal anomalies would quickly be followed by cfDNA-based tests to "read" the entire fetal genome. This did not happen: while in 2020 it is technically possible to sequence the fetal genome using cfDNA, it is simpler and less expensive to sequence DNA extracted from fetal cells in the amniotic liquid. Experts failed to predict the persistently high price of cfDNA sequencing. And they did not discuss the possibility that the inclusion of NIPT into already-existing national screening programs for "Down risk" would follow a different path from the market-based diffusion of the same test. Finally, they did not anticipate that in some cases a cfDNA-based test would reveal an unsuspected maternal pathology, usually a malignancy (Bianchi et al., 2015).

Once the tests—now renamed NIPT—-were available on the market, the questions asked about them, especially in countries with a national health system changed. Some scholars continued to invoke the potential consequences of cfDNA-based whole-genome scans (e.g. Ravitsky, 2015; Shakespeare, 2015). But discussions now focused mainly on the implications for existing screening programs for major chromosomal anomalies. Many of the questions asked in these debates, for instance about evaluating the specificity and reliability, cost and efficacy of a given test, its reimbursement by insurers, or the need for informed consent, had already been raised in earlier debates about the use of serum markers to determine "Down risk". Debates about NIPT also shared with earlier discussions a tendency to eschew the thorny issue of selective abortion for fetal 
indications, and an implicit consensus that professionals would be the main gate keepers for access to tests, while such access would also be indirectly regulated through health insurers' reimbursement policies (CCNE, 2013; Belgium Advisory Committee, 2016; Horn, 2019).

Other potentially problematic aspects of NIPT were seen as specific to this technology, including the exclusive development and diffusion of NIPT by commercial firms, and the risk that NIPT would be integrated into routine surveillance of pregnancy without adequate counseling. The rapid development of genetic counseling in the 1970s had been linked to the need to help women decide whether to undergo amniocentesis, associated as it was with increased risk of a spontaneous abortion (Stern, 2012). Since NIPT does not carry such a risk, it was feared that women would take this "simple blood test" without being adequately informed about the nature of the test and the precise meaning of a "positive" result. Women who underwent NIPT, but also some health care providers, might confuse NIPT's high specificity and sensitivity with positive predictive value - that is, the probability that a woman who tests positive for a specific fetal anomaly does indeed carry a fetus with this anomaly, a variable which depends on the frequency of that anomaly in the tested population (Shakespeare, 2015; Lewis, 2017, Birko et al., 2018).

v. NIPT outside North America and Western Europe: Brazil and China.

Diagnostic technologies based on examining cfDNA in the maternal circulation rapidly reached Brazil, where they took a specific form. From the early 2000s on, several years before cfDNA-based tests for Down syndrome became available, Brazilian 
laboratories developed cfDNA-based tests to detect fetal sex (Levi et al., 2003), Women do not have Y chromosome markers, and the presence of Y chromosomal DNA in the blood of a pregnant woman thus indicates that she is carrying a male fetus. Testing for fetal sex is possible from the sixth to seventh week of pregnancy, and is much simpler and cheaper than cfDNA-based tests for abnormal chromosome number. Medical reasons to detect fetal sex early in pregnancy include when a woman is at risk of giving birth to a child with congenital adrenal hyperplasia (CAH). In such cases, some experts recommend early tests to determine if the fetus is female, followed by treatment with the steroid dexamethasone to attenuate "virilization" of the fetus-whereas such treatment, and its secondary effects on the mother, can be avoided if the fetus is male (New et al., 2014). However, there are also many non-medical reasons why a woman might want early knowledge of the fetus's sex, from curiosity and a desire to know more about her future child, to a wish to abort a fetus of the "wrong" sex.

Similar tests, including Baby Gender Mentor ${ }^{\mathrm{TM}}$ (manufactured by Acu-Gen Biolab Inc.) and Pink or Blue ${ }^{\circledR}$ (Consumer Genetics Inc.), also quickly became available in the USA — marketed directly to pregnant women as a means of determining their fetus's sex using blood from a finger prick, at a price of approximately $\$ 250$. Experts were critical of these tests, mainly because firms were not required to maintain high standards of reliability, but also because of the risk of prenatal sex selection, especially in societies which favor male children (Bianchi, 2006; Hall et al, 2009). With the commercialization of "basic" NIPT which included an option to reveal the fetus's sex, tests that detected only fetal sex became less visible, at least in Western Europe and North America.

Such tests remained popular in Brazil, however. Indeed, locally-produced tests that reveal the "baby's sex" early in pregnancy continue to be offered to middle-class women, 
sometimes as a part of a prenatal care package in a private clinic. The tests are relatively inexpensive, their price in 2015 was at around 300-400 reals (approximately \$80-\$100), an acceptable sum for a middle-class woman. Street corner obstetrical ultrasound clinics can reveal fetal sex for a much lower price (in some cases as little as 20-30 reals), but this is only possible in the second trimester of pregnancy, typically at 20-22 weeks (Mirlesse, 2014). The widespread preference for earlier tests is linked to the cultural importance, in Brazil, of knowing the fetus's sex: as soon as this is known, the future child becomes "our baby," is given a name, and middle-class families start shopping for gender-appropriate clothes and accessories (Chazan, 2008). Announcement of a fetus's sex is becoming a culturally significant event in the US too, celebrated in the increasingly popular "sex revealing" parties (Vincent, 2018). But detection of fetal sex as a key milestone in making the future child "real" is not a universal trait. In Israel, pregnancy is perceived as fraught with danger, and Israeli-Jewish families do not celebrate baby showers or organize sexrevealing parties; some even refrain from purchasing baby clothes and furniture until the child's birth. On the other hand, Israeli anxiety about pregnancy encourages the use of a wide range of prenatal tests (Ivry, 2009; Zielinska and Löwy, 2017).

Brazilian families do not have a strong preference for male children, and Brazilian gynecologists state that the detection of fetal sex has no incidence on rates of termination of pregnancy. Detection of chromosomal anomalies in the fetus has a very different meaning. Abortion for fetal indications is illegal in Brazil, with the sole exception of anencephaly, and the Brazilian national health system does not offer prenatal diagnosis of fetal impairments (Diniz and Medeiros, 2010). However, only poor Brazilian women use the state-provided maternity services, while middle- and upper-class women use the services of private gynecologists. These gynecologists, especially those working in upper- 
end maternity clinics, tend to prescribe numerous diagnostic tests which, together with the use of sophisticated medical imaging equipment, are seen to stand for cutting-edge, highquality medicine. Among other tests, middle- and upper-class pregnant women frequently undergo serum marker and nuchal translucency tests for "Down risk" at the end of the first trimester of pregnancy. If these tests indicate a higher than average risk of fetal anomaly, the woman usually undergoes amniocentesis, and if the result is "positive," she can elect to have an illegal—but safe_-abortion in Brazil or travel abroad to legally terminate the pregnancy. The small number of children with inborn defects born in private hospitals and clinics indirectly indicates that affluent Brazilian women commonly undergo selective termination of pregnancy (Horovitz at al., 2013).

In 2013, two US producers of NIPT_-Ariosa, producer of the Harmony test, and Natera, producer of the Panorama test—signed agreements with Brazilian laboratories to offer NIPT to Brazilian women. Regulation was not an issue, since the tests were offered only in the weakly regulated private health sector. Discussion of these tests in the Brazilian media, and publicity leaflets issued by commercial test providers, stressed that the new technology would help families to prepare for the birth of a "special needs" child. Laboratories offering NIPT in Brazil also took into account the fact that the average maternal age there is lower than in industrialized countries. Brazilian publicity for the Panorama test, for instance, explains that while "conventional" NIPT detects only trisomy 21, 13 and 18, a "complete" test also detects several chromosomal deletions. Down syndrome, the leaflet adds, is more frequent in older women, while the risk of microdeletions does not depend on woman's age, and pregnant women under thirty are therefore at higher risk of having a child with a microdeletion than with Down syndrome, so are advised to have a "complete" test. 
Initially, many specialists thought that NIPT would only find a limited distribution in Brazil, mainly because the price—at that time approximately $\$ 1200 \_$was four to five times higher than screening for Down risk through a combination of serum tests and ultrasound. In only a year, however, NIPT had become firmly integrated into prenatal testing in the Brazilian private health sector. Again, cultural factors explain this rapid takeup. In Brazil, private health insurance does not reimburse many of the services provided by private maternity clinics, and women who choose such clinics are often willing to pay for services from their own pockets. Gynecologist interviewed for my study of prenatal diagnosis in Brazil explained that in a sub-culture that puts to the fore the consumerist aspect of maternity, the purchase of an expensive cfDNA-based test may be seen by some women as a less frivolous pregnancy- and childbirth-related expense than the purchase of items such as an expensive baby pram. Besides, the price of NIPT, though high, is lower than other health expenses such as a consultation with a well-known ultrasound expert. Consequently, while the majority of Brazilian users of NIPT are "low risk" women, the test's cost does not discourage affluent women who want rapid reassurance that "the baby is all right", and ultrasound experts working in upper-end gynecological clinics attested that their patients often arrive for their 12-weeks ultrasound examination with NIPT results.

The free-market trajectory of cfDNA-based tests in Brazil is in marked contrast to what happened in another intermediate economy, namely China. Chinese NIPT was a local product. Between 2011 and 2014 several Chinese private companies, including Beijing Genomic Institute (BGI) and Berry Genomics (active also on the European market), marketed NIPT for Down syndrome and other aneuploidies (Heger, 2014; Heger, 2015). Chinese cfDNA-based tests were less expensive than Western ones, but their price (2000- 
3000 RMB, about $\$ 250-350$, in 2016) still made them too expensive for lower-class users. The Chinese NIPT tests circulated freely on the internal market for about three years, but in February 2014, the Chinese Food and Drug Administration and the National Health and Family Planning Commission announced that the diffusion of all prenatal genetic tests, including NIPT, was suspended until the implementation of a new regulation. This decision was taken on the grounds that the commercial market for genetic testing was chaotic, the quality of the tests was highly variable, and there was no guarantee that the companies that produced genetic tests could deliver what they promised. In June 2014 the Chinese regulatory agencies granted conditional marketing permits to a small number of cfDNA-based tests produced by well-known manufacturers. These tests are available on the private market. In addition, however, several Chinese provinces incorporated NIPT for selected indications into state-sponsored parental care, and proposed partial reimbursement of the tests' costs (Zeng et al, 2016; Jin et al, 2017). The Chinese approach, in which NIPT is assimilated to other genetic tests and its providers are strictly controled by the state, contrasts with the attitude of Western European countries and the US which do not regulate private purchase of cfDNA-based tests prescribed by a woman's doctor.

v. Discussion: global markets, situated uses.

The short history of NIPT displays the complicated relationship between the global and the local in health care. Social scientists increasingly recognize the need to pay attention to the contexts that shape the production, diffusion and regulation of new diagnostic and therapeutic approaches, and acknowledge that one size does not fit all. 
Diagnostic innovations-like other technological innovations - come into being in a full world. They compete with already existing technologies and are shaped by institutional and organizational variables, economic and political considerations, local medical cultures, and legal and regulatory frameworks. In the case of NIPT, the regulation of marketing and use tended to follow the general rules already in place in different countrie to govern the marketing of related tests, notably those that detect other serum markers for elevated risk of having a child with Down syndrome. National regulatory instances were mainly concerned about cost-efficacy and reliability. In practice, the diffusion of this biomedical innovation reflected national and regional differences in structure of health insurance, cultural variables" writ large, and, in many Western European countries, the history of implementation of nationwide screening for "Down risk."

NIPT was introduced by biotechnology companies that prioritized private or semiprivate markets and tests that detect major chromosomal anomalies (Chandrasekharan et al, 2014; Minear et al, 2015). However, one could imagine a different configuration, in which this diagnostic technology was supported by public or charitable funding, and harnessed to the goal of improving prenatal care in lower-income countries. In such countries, womenespecially those who live outside urban centers-have limited access to advanced diagnostic approaches such as high-quality obstetrical ultrasound and amniocentesis. NIPT could partly compensate for the shortage of qualified gynecologists and ultrasound experts because blood samples of pregnant women can be collected by community health workers and sent to a central laboratory. As a result, more women could receive information about fetal anomalies and - if they live in a society in which abortion is not criminalized—could make an informed choice about the future of their pregnancy (Allyse et al., 2015). One can also imagine cfDNA-based tests tailored to the health needs of populations outside North 
America and Western Europe, by being calibrated to detect locally important diseases such as thalassemia or sickle cell anemia (Mozersky et al, 2017). For now, however, the latter possibility is purely theoretical. Technologies incorporate in their design the values that have guided their development. We cannot know how a cfDNA-based diagnostic approach shaped by different values and considerations might have looked, or how it could have been distributed and regulated.

In 2009 the UK-based Public Health Genomics Foundation published a report on the ethical, legal and social issues arising from cell-free nucleic acid technologies. The report included a disclaimer, stating that since the field of non-invasive prenatal diagnosis is extremely dynamic and technology is developing very rapidly, its analysis was only accurate as of the publication date (Hull et al, 2009). The same disclaimer is valid for the present paper too; it provides a—surely incomplete—overview of the rolling out of NIPT as of spring 2020. The observation that many of the publications that discussed cfDNAbased tests before they came into practice rapidly became obsolete, is an invitation to be modest. It is not possible to know whether NIPT will continue to be employed in its present form, will undergo important modifications, or will be replaced by a very different approach to screening. Nor can we know whether it will be submitted to more formal regulation, or if its use will continue to be shaped by the decisions of doctors who prescribe this test and by women's access to it. However, it is reasonable to assume that whatever the future of NIPT will be, it will continue to be strongly affected by situated variables. It is also reasonable to assume that while it is possible to collect at least partial information on cfDNA-based tests prescribed by health professionals and employed in the framework of medical supervision of pregnancy, other, less visible, and, in some, countries illegal uses of this technology, such as sex selection, may exist as well. The central role of 
industry in the development of this diagnostic innovation, strong links between NIPT and the highly contentious topic of selective abortion, and the weak regulation of marketing of tests, may favor the existence of gray zones of cfDNA-based prenatal testing.

Bibliography.

Agarwal, A., Sayres, L., Cho, M.K., Cook-Deegan; R., and Chandrasekharan, S. (2013). Commercial landscape of noninvasive prenatal testing in the United States. Prenatal Diagnosis 33: 521-531.

Allyse M., Minear, M.A., Berson, E., Sridhar S., Rote M., Hung A, and Chandrasekharan S. (2015). Non-invasive prenatal testing: a review of international implementation and challenges. International Journal of Women's Health, 7:113-126.

Allyse, M., Chandrasekharan, S (2015). Too much, too soon?: Commercial provision of noninvasive prenatal screening for sub chromosomal abnormalities and beyond. Genetics in Medicine, 17(12), 958-961

Allyse, M., and Wick,M., (2018). Noninvasive prenatal genetic screening using cell-free DNA. JAMA, 320(6): 591-592. 
American College of Obstetrics and Gynecology (ACOG). Committee Opinion No. 640: Cell-Free DNA Screening For Fetal Aneuploidy. Obstetrics and Gynecology, ;126(3):e31-7. doi: 10.1097/AOG.0000000000001051.

Belgium Advisory Committee on Bioethics (2016). Opinion no. 66 - non-invasive prenatal testing (NIPT).

https://www.health.belgium.be/en/opinion-no-66-non-invasive-prenatal-testing-nipt (accessed 10 April, 2019).

Benn P. and Chapman A. (2009). Practical and ethical considerations of noninvasive prenatal diagnosis. JAMA, 301(20): 2154-2156.

Benn P and Chapman A. (2010) . Ethical challenges in providing noninvasive prenatal diagnosis. Current Opinion in Obstetrics and Gynecology, 22:128-134.

Benn, P., Curnow, K, , Chapman, S., Michalopoulos, S.N., Hornberger, J. and Rabinowitz, M., (2015). An economic analysis of cell-free DNA non-invasive prenatal testing in the US general pregnancy population. PLoS One, 10(7): e0132313. doi:10.1371/journal.pone.0132313.

Bianchi, D. (1998).Fetal DNA in maternal plasma: the plot thickens and the placental barrier thins. American Journal of Human Genetics 62: 763-64 
Bianchi, D. (2006). At-home fetal DNA gender testing: caveat emptor. Obstetrics and Gynecology, 107(2): 216-218.

Bianchi, D. (2010). From Michael to microarrays: 30 years of studying fetal cells and nucleic acids in maternal blood. Prenatal Diagnosis 30: 622-623.

Bianchi, D., Chudova, D., Sehnert, A. J., et al. (2015). Non invasive prenatal testing and incidental detection of occult maternal malignancies. JAMA, 14(2):162-169.

Bianchi, D. (2019). Turner syndrome: New insights from prenatal genomics and transcriptomics. American Journal of Medical Genetics, in press. DOI: 10.1002/ajmg.c.31675.

Birko, S., Lemoine, M.E., Nguyen, M.T., and Ravitsky V. (2018). Moving towards routine non-invasive prenatal testing (NIPT). Challenges to women's autonomy. OBM Genetics, 2(2): doi:10.21926/obm.genet.1802018.

Boyd P., and Game, E. (2011). Special Report, Prenatal Screening Policies in Europe, 2010. Ulster, Eurocat Central Registry.

Blume, S. (1992). Insight and Industry: On the Dynamics of Technological Change in Medicine. MIT Press. 
CCNE- National Consultative Ethics Committee for Health and Life Sciences, France. (2013). Opinion $n^{\circ} 120$. Ethical issues in connection with the development of foetal genetic testing on maternal blood.

https://www.ccne-ethique.fr/en/publications/ethical-issues-connectiondevelopment-foetal-genetic-testing-maternal-blood (accessed 10 April, 2019).

Chachkin, C.J. (2007). What potent blood: non-invasive prenatal genetic diagnosis and the transformation of modern prenatal care. American Journal of Law and Medicine, 33(1): 9-53.

Chandrasekharan, S., Minear, M.A., Hung, A. and Allyse, M.(2014). Noninvasive prenatal testing goes global. Science Translation Medicine, 6, $231 \mathrm{fs} 15$ (2014).

Chen K. , White K., Shabbeer J. and Schmid M. (2019).Maternal age trends support uptake of non-invasive prenatal testing (NIPT)in the low-risk population. The Journal of Maternal-Fetal \& Neonatal Medicine, 32(23):4039-4042

Chazan -Krakowsky, L. 2008. E ta gravida mesmoé E ele e lindo! A construcao de 'verdades" na ultra-sonografia obstetrica. Manguinhos, 15: 99-116.

Chitty, L., and Kroese, M. (2015). "Editorial: Realising the promise of noninvasive prenatal testing," British Medical Journal, 350: h1792. 
Crombag, N., Vellinga,Y., Kluijfhout, S., et al. (2014). Explaining variation in Down's syndrome screening uptake: comparing the Netherlands with England and Denmark using documentary analysis and expert stakeholder interviews? BMC Health Services Research 14 : 437. doi: 10.1186/1472-6963-14-437.

Dar, P., Curnow, K.J. Gross, S. et. al.,(2014). Clinical experience and follow-up with large scale single-nucleotide polymorphism- based noninvasive prenatal aneuploidy testing," American Journal of Obstetetrics and Gynecology 211: 527.e1-527.e17. doi: 10.1016/j.ajog.2014.08.006

De Jong, A., Dondorp, W.J., Frints, S., de Die-Smulders, C. and de Wert, G. (2011). Advances in prenatal screening: the ethical dimension. Nature Reviews, Genetics, 12: 657-663.

Dondorp W., de Wert G., Bombard Y et al (2015). Non-invasive prenatal testing for aneuploidyand beyond: challenges of responsible innovation in prenatal screening, European Journal of Human Genetics, 23(11):1438-1450.

Diniz D, Medeiros M. Abortion in Brazil: a household survey using the ballot box technique. Ciencia e Saude Coletiva, 2010;15:959-66.

Dommergues, M., Mandelbrot,L., Mahieu-Caputo, D. , et al., 'Termination of pregnancy following prenatal diagnosis in France: how severe are the foetal anomalies?', Prenatal Diagnosis 30 (2010): 531-39. 
Dondorp, W., de Wert, G., Bombard, Y et al. (2015). Non-invasive prenatal testing for aneuploidy and beyond: challenges of responsible innovation in prenatal screening . European Journal of Human Genetics, 23 : 1438-1450.

Evans M. and Vermeesch J. 16 (2016): Current controversies in prenatal diagnosis 3: industry drives innovation in research and clinical application of genetic prenatal diagnosis and screening. Prenatal Diagnosis, 36, 1172-1177.

Greely, H. (2011), Get ready for the flood of fetal gene screening," Nature ,469: 289-91.

Greely H and King, J. (2010). The coming revolution in prenatal genetic testing," AAA Professsional Ethics Report 23: 1-8.

Greene, M. (2014) "Screening for trisomies in circulating DNA," New England Journal of Medicine 370: 874-875.

Hall, A., Bostanci, A., and John, S., (2009). Ethical, legal and social issues arising from cell-free fetal DNA technologies. Appendix 3 to the repport, Cell-free fetal nucleic acids for non-invasive prenatal diagnosis. Foundation for Genomics and Population Health,UK. (PHG), 2009. 
HAS-Haute Authorite de Santé, France. (2019). Place des tests AND libre circulant dans sang maternel dans le dépistage de la trisomie fotale.

https://www.has-sante.fr/portail/jcms/c_2768510/fr/place-des-tests-adn-librecirculant-dans-le-sang-maternel-dans-le-depistage-de-la-trisomie-21-foetale (accessed 10 April, 2019).

Hashiloni-Dolev Y, Nov-Klaiman, T. and Raz A. (2019)., Pandora's pregnancy: NIPT, CMA, and genome sequencing: A new era for prenatal genetic testing. Prenatal Diagnosis, 39: 859-865

Hayden, E.C. (2014) . Prenatal-screening companies expand scope of DNA tests, but the increasingly accurate analyses carry the ethical dilemma of uncertain outcomes. Nature, 507: 19.

Haymon, L. (2011). Non-Invasive Prenatal Genetic Diagnosis (NIPD). Council for Responsible Genetics (US), 2011.

Heger, M. (2014).China's Berry Genomics runs more than150K NIPT; Aims to move into single-gene disorders, PGS. Genome Web, January 22, 2014.

Heger, M. (2015). Clinical NGS market in China poised to take off as China FDA looks to establish guidelines. Genome Web, September, 23, 2015. 
Herzenberg, L., Bianchi, D., Schroder, J., Cann H., and Iverson, M. (1979). Fetal cells in the blood of pregnant women: detection and enrichment by fluorescence-activated cell sorting. Proceeding of the National Academy of Sciences (USA) 76: 1453-1455.

Hobby, G. (1985). Penicillin: Meeting the Challenge, Yale University Press.

Horn, R. (2019). La France et la Grande-Bretagne à l'ère de la médecine génomique : Nouveaux défis éthiques en médecine de la reproduction. Médecine/Sciences, 35 : $163-8$

Horovitz, D., de Faria Ferraz, V., S Dain S., and Marques-de-Faria, A.P. (2013). Genetic services and testing in Brazil, Journal of Community Genetics, 4: 355-375.

Howard-Bath A, Poulton A., Halliday J. and Hui L. (2018). Population-based trends in the prenatal diagnosis of sex chromosome aneuploidy before and after noninvasive prenatal testing. Prenatal Diagnosis, 38:1062-1068.

Ivry, T. (2009). Ultrasonic picture show and the politics of threatened life . Medical Anthropology Quaterly, 23(3): 189-211.

Jin, J., , Junwen Yang, J., Chen, Y.,and Huang,J. (2017). Systematic review and meta-analysis of non-invasive prenatal DNA testing for trisomy 21: implications for implementation in China. Prental Diagnosis, 37 : 864-873. 
Kornman L., Palma-Dias R., Nisbet D, Scott F., Menezes M., da Silva Costa F., and McLennan A. (2018). Non-invasive prenatal testing for sex chromosome aneuploidy in routine clinical practice. Fetal Diagnosis and Therapy, 44: 85-90.

Landau M. (2012)., Yuk-Ming Dennis Lo. Clinical Chemistry, 58:4, 784-786.

Levi, J.E., Silvano Wendel, S., and Takaoka , D.S. (2003). Determinação pré-natal do sexo fetal por meio da análise de DNA no plasma materno. Revista Brasileira de Ginecologia e Obstetrica, 25(9): 687- 690.

Lewis, C., Hill, M., and Chitty, L. (2017). Offering non-invasive prenatal testing as part of routine clinical service. Can high levels of informed choice be maintained? Prenatal Diagnosis. 37: 1130-1137.'

Lo, D.Y., Wainscoat J.S., Gillmer M.D., Patel P., Sampietro M, and Fleming K. (1989). Prental sex determination from maternal peripheral blood. The Lancet, ii (8676):1363-1365.

Lo, D.Y., Corbetta, N.,Chamberlain, P., Rai,V., Sargent, I., Redman, C., and Wainscoat, J. (1997). Presence of fetal DNA in maternal plasma and serum. The Lancet, 350: $485-87$. 
Lo, D.Y. (2015). Noninvasive prenatal diagnosis: from dream to reality; Clinical Chemistry 61: 32-37

Lock, M. (2001). The tempering of medical anthropology: troubling natural categories," Medical Anthropology Quarterly 15: 478-92.

Löwy, I. (2014). Prenatal diagnosis : The rresistible rise of the 'visible fotus.' Studies in History and Philosophy of Biological and Biomedical Sciences, 47: 154-162.

Löwy, I. (2017). Imperfect Pregnancies: A History of Birth Defects and Prenatal Diagnosis. Johns Hopkins University Press.

Löwy I (2018). Tangled Diagnoses: Prenatal Testing, Women, and Risk. Chicago University Press, 2018.

Malan, V., Bussieres, L., Winer, N., et al., (2018). Effect of cell-free DNA screening vs direct invasive diagnosis on miscarriage rates in women with pregnancies at high risk of trisomy 21: a randomized clinical trial. JAMA, 320 (6): 557-565.

Marks, L. (2015). The Lock and Key of Medicine: Monoclonal Antibodies and the Tranformation of Health Care. Yale University Press. 
Metzler, I. (2020). Imaginaries as infrastructures? The emergence of non-invasive prenatal testing in Austria, Biosocieties, in press. https://doi.org/10.1057/s41292-019$00171-7$

Minear, M.A., Lewis, C., Pradhan, S., and Chandrasekharan, S. (2015). Global perspectives on clinical adoption of NIPT. Prenatal Diagnosis, 35(10): 959-967.

Mirlesse,V. Diagnostic prénatal et médecine fæetale. Du cadre des pratiques à l'anticipation du handicap. Comparaison France-Brésil, unpublished $\mathrm{PhD}$ thesis, Paris XIII University, 2014.

Mozersky J, Ravitsky V., Rapp, R., Chandrasekharan, S., and Allyse, M. (2017). Toward an ethically sensitive implementation of noninvasive prenatal screening in the global context. Hasting Center Report, March-April, 2017: 41-49.

New, M., Tong, Y.K., Yuen, T., et al. (2014). Noninvasive prenatal diagnosis of congenital adrenal hyperplasia using cell-free fetal DNA in maternal plasma. Journal of Clinical Endocrinology and Metabolim, 99: E1022-E1030.

Palomaki, G.E., Deciu ,C., Kloza E.M., et al. (2012). DNA sequencing of maternal plasma reliably identifies trisomy 18 and trisomy 13 as well as Down syndrome: an international collaborative study. Genetics in Medicine 14: 296-305. 
Parthasarathy, S. (2007). Building Genetic Medicine: Breast Cancer, Technology, and the Comparative Politics of Health Care. Cambridge, MA: The MIT Press.

Philips, K. Deverka P., Hooker G and Douglas M. (2018) Genetic tests availability and spending: Where are we now? Where are we going? Health Affairs, 37(5): 710-716.

Proffitt, A. (2013). Advances in prenatal molecular diagnosis., Bio-IT- World October 7, 2013.

http://www.bio-itworld.com/2013/10/7/predicting-the-future-for-noninvasiveprenatal-testing.html (accessed 10 April, 2019).).

. Ramdaney, A, Hoskovec, J., Harkenrider, J., Soto, E., and Murphy, L. (2018) Clinical experience with sex chromosomes aneuploidies detected by non-invasive prenatal testing (NIPT): accuracy and patient decision making. Prenatal Diagnosis, 38(11): 841-848.

Ravitsky, V. (2015). Background paper: Non-Invasive Prenatal Testing (NIPT). Identifying key clinical, ethical, social, legal and policy issues. Nuffield Council on Bioethics background paper, November 2015.

Romero R. (2018). A Profile of Dennis Lo, DM, DPhil, FRCP, FRCPath, FRS. American Journal of Obstetrics and Gynecology, 218 ( 4): 371-378 
Schwennesen, N., Nordahl Svendsen M., and Koch, L. (2010) Beyond informed choice: prenatal risk assessment, decision-making and trust," Clinical Ethics 5: 207-16;

Shakespeare, T. (chair) (2017). Nuffield Council on Bioethics Working Group Report: Non Invasive Prenatal Testing: Ethical Issues. Nuffield Council on Bioethics 2017.

Stein, Z., Susser M.,and Guterman, A. (1973). Screening programme for Down Syndrome," The Lancet, 301, i: 305-310.

Stern, A.M. (2012). Telling Genes: The Story of Genetic Counseling in America. Johns Hopinks University Press.

Stoll, .K. (2013). NPIS is not diagnostic—convincing our patients and convincing ourselves," The DNA Exchange Blog, July 11, 2013, http://thednaexchange.com/2013/07/11/guest-post-nips-is-not-diagnosticconvincing-our-patients-and-convincing-ourselves/ (accessed 10 April, 2019).).

Taneja P., Snyder H., de Feo E. Kruglyak K. , Halks-Miller M. , Curnow K., and Sucheta Bhatt S. (2016). Noninvasive prenatal testing in the general obstetric population: clinical performance and counseling considerations in over 85000 cases. Prenatal Diagnosis, 36: 237-243 
Thomas, G. (2017). Down's Syndrome Screening and Reproductive Politics. London, Routledge.

Twiss, P, Hill, M., Daley, R., and Chitty, L.S. (2014). Non-invasive prenatal testing for Down syndrome. In Seminars in Fetal and Neonatal Medicine 19, 1: 9-14.

Vassy, C. (2006). From a genetic innovation to mass health programmes: The diffusion of Down's Syndrome prenatal screening anddiagnostic techniques in France. Social Science \& Medicine, 63: 2041-2051.

Vassy C., Rosman, S., and Rousseau, B. (2014). From policy making to service use. Down's syndrome antenatal screening in England, France and the Netherlands; Social Science and Medicine 106: 67-74

Ville I. et al. (2013). Diagnostic prénatal et prévention des handicaps, final report of the contract ANR 09-SSOC- 026, French National Research Agency.

Vincent, M.R. (2018). People are going way over the top with their gender-reveal parties these days. CNN, 8 June 2018.

https://www.cnn.com/2018/06/08/health/gender-reveal-parties-trnd/index.html (accessed 10 April, 2019). 
Williams, C., Sandall, J., Lewando-Hundt, G., Heyman, B., Spencer, K., and Grellier ,R. (2005). "Women as moral pioneers? Experiences of first trimester antenatal screening. Social Science \& Medicine 61 1983-92.

Wright, C. (coordinator). Cell-free fetal nucleic acids for non-invasive prenatal diagnosis: Report of the UK Expert Working Group. (2009). PHG Foundation, January 7 , 2009.

Zeng X., Zannoni, L., I. Löwy, I. and S. Camporesi, S. (2016). Localizing NIPT: Practices and meanings ofnon-invasive prenatal testing in China, Italy,Brazil and the UK. Ethics Medicine and Public Health, 2(3): 392-401.

Zielinska, A. and Löwy, I. (2017). The Golden Helix: Origins, ethnicity and preconception genetic screening in Israel. Biosocieties, 13 : 323-348 
I am indebted to the organizers of the workshop "Celebrating 50 Years of Wilson and Jungner" (London, June 19-19, 2018): Stuart Hogarth, Steve Sturdy and Fiona Miller, and to all the participants in this workshop for stimulating discussions that greatly improved my understanding of screening. My other debt is to Diane Paul, Robert Resta and Kathy Stoll for helping me to improve my statements about prenatal screening in the US and the uses of NIPT in that country, and to Steve Sturdy for his generous help with reviewing the text, clarifying my arguments, and correcting my English 
Uses of non -invasive prenatal diagnosis were often shaped by commercial firms In spite of its limitations, non -invasive prenatal diagnosis is a marketing success.

There are important national differences in use of non-invasive prenatal diagnosis.

Stratified uses of non -invasive prenatal diagnosis produce situated fetal risks. 
Non-invasive prenatal testing: a diagnostic innovation driven by commercial interests and the regulation conundrum.

\section{Abstract}

Non-invasive prenatal testing (NIPT) detects a high probability of fetal chromosomal anomalies through the analysis of free circulating fetal DNA (cfDNA) in maternal circulation. This diagnostic method was developed exclusively by commercial firms, who hoped to reach a huge potential market, with a test, expected to be risk-free, reliable, inexpensive, and able to detect a wide range of genetic traits of the future child. As for now, the majority of the predictions about the scope and uses of NIPT did not materialize. In 2018 NIPT detects only a limited number of genetic anomalies, its results has to be confirmed by amniocentesis. Nevertheess NIPT became a commercial success.The diffusion of this test led to development of two distinct configurations. In the first, gradually implemented in countries with a state- sponsored screening for "Down risk", women defined as "high risk" are offered a variant of NIPT that detects only three autosomal aneuploidies: trisomy 21,13 and 18 , an non-absolute but in practice efficient regulation of its uptake. In the second, diffused in countries without state -sponsored screening for Down risk, several versions of NITP are available on the free market and, while professional associations issued guidelines for the use of this test, these guidelines were mostly disregarded. Users who can afford to pay for NIPT from their pocket can decide whether, when and how they wish to use this diagnostic 
technology, while those who rely on reimbursement of NITP by their insurer depend on the insurer's decision which tests they will cover. Differences in access to NIPT in different countries and social strata produce a situated awareness of risk of fetal impairment and local fetal biologies.

Keywords:

pregancy, fetus, selective abortion, amniocentesis ,circulating free fetal DNA, non invasive prenatal diagnosis, genetic testing, Down syndrome.

$*$

i. Introduction: NIPT—distinct trajectories of a diagnostic innovation.

Noninvasive prenatal testing (NIPT) studies free circulating fetal DNA (cfDNA) in maternal serum, in order to identify fetal anomalies. This diagnostic method is proposed by numerous biotechnology companies who compete in world-wide market of prenatal testing. The aim of of cfDNA-based diagnostic methods, was to provide a reliable and risk-free method of visualization of selected genetic anomalies of the fetus, above all the presence of an abnormal number of chromosomes. A more remote goal was to extend the scope of analysis of fetal DNA and provide a "reading" of the entire fetal genome. (e.g., Benn and Chapman, 2010; Greely, 2011). In 2018 it is too early to decide what the future of NIPT will be. Nevertheless the first seven years of diffusion of this diagnostic approach (2011-2018) point to a development absent from debates that 
preceded its marketing: the existence of two distinct models of its distribution, one introduced in countries with preexisting, nation-wide structures of screening for Down risk, and the second in countries devoid of either national/ centralized health care system, a systematic screening for Down syndrome risk, or both.

In the first configuration, NIPT is distributed mainly through a national health system and is indirectly regulated by the rules that governscreening for "Down risk,". In this configuration, NIPT is limited to the search of trisomy 21,13 and 18. It is a "second level screen," proposed only to women previously defined as being at a high risk of carrying a trisomic fetus through a "first level screening": a combination of serum markers and obstetrical ultrasound. In this configuration, NIPT is is regulated by the same rules (reliability, reproducibility) that govern the use of tests for for serum markers of "Down risk." In the second configuration, NIPT is implemented in countries, such as the US, without a national health system, or as Brazil, where the national health system does not cover screening for fetal anomalies because abortion is illegal. In this configuration NIPT is above all a consumer item available on the market. It can be purchased by high and low risk women, and its users can decide whether they want to know only if the fetus does not have trisomy 21,13 or 18 , or wish also to receive additional information.

The two configurations, the integration of NIPT within the existing framework of screening for Down within a national health care system, and the purchase of NIPT on a free market, are ideal types. In practice, intermediary situations can exist. Moreover, in countries in which a national health system limits the use of NIPT to screening for three major autosomal aneuploidies in high risk women, affluent health care users can purchase other forms of cfDNA based screening/ testing, while in 
countries in which NIPT is diffused on the free market, choices of women/ couples who cannot afford paying for this test from their pocket are restricted by rules that govern the reimbursement of specific variants of this test by their health insurance provider. In these countries, insurance providers informaly regulate the scope of NIPT use. Nevertheless, between 2011 and 2018, the use of cfDNA- based tests was shaped by the structure of health care is a given country, local regulatory framework, legal constraints, cost/efficacy considerations that govern decisions of health insurers, and, above all, previously existing pattern of screening for "Down risk."

\section{ii. Screening for Down risk before NIPT.}

The cfDNA based diagnostic technologies are today usually called NIPT, and sometimes noninvasive prenatal screening, or NIPS. The term "noninvasive prenatal testing" may, however, be misleading. Historically, first prenatal tests, introduced in late 1960s, were grounded in invasive technologies: the collection of fetal cells, either from the amniotic fluid (amniocentesis), or the fetal part of the placenta (chorionic villus sampling-CVS). Fetal cells were then tested for the presence of abnormal number of chromosomes (aneuploidy) or biochemical markers of a hereditary metabolic disease. Gynecologists and public health experts were especially concerned about the risk of Down syndrome (trisomy 21). Women of "advanced maternal age" who are at a higher risk to give birth to a Down syndrome child, were advised to undergo amniocentesis or CVS in order to learn whether the fetus has three copies of chromosome 21. Invasive tests were, however, linked with risk of a spontaneous abortion of a healthy fetus. Moreover, many children with trisomy 21 are born to younger women, but since in 
these women the risk of loss of a pregnancy following an invasive test was seen as higher than a risk to have a Down syndrome child, physicians did not recommend this test to women under 35. (Löwy, 2014).

In the early 1970s some experts proposed to offer amniocentesis for Down risk to all the pregnant women (Stein et al, 1973). This was not a realistic proposition: amniocentesis was too risky and too expensive to became a generalized prenatal test. In the 1980s and early 1990s experts found out that fetuses with increased nuchal translucency (accumulation of liquid behind fetal neck) at 11-12 weeks of pregnancy were at higher risk of trisomy 21 . They also found out that changes in levels of biochemical markers in the pregnant woman serum indicated a higher probability that the fetus has an abnormal number of chromosomes. A algorithm that combined data provided by ultrasound and serum tests with woman's age, calculated the woman's individual "risk number," that is her odds to carry a fetus with chromosomal anomaly. Those with a "risk number" higher than a predetermined value ( typically 1 to 200 to 1 to 300) were offered a possibility to undergo an invasive test. The new approach made possible the implementation of screening of all the pregnant women for "Down syndrome risk." Such screening favored in turn a rapid extension of prenatal diagnosis. It was also the moving force behind the development of NIPT (Löwy, 2017).

Screening for Down risk was introduced in several Western European countries in which prenatal care is partly or totally covered by a national health insurance, but the specific form of such screening and its uptake are highly variable (Boyd and Game, 2011). Often a screening was first proposed to women in the framework of large-scale clinical trials. When these trials indicated that the method is efficient, it was integrated into a national system of surveillance of pregnancy. In countries devoid of national 
health system, women's decisions whether to screen for Down risk were strongly affected by advice provided by their health providers, and their access to resources. In these countries, fewer women underwent screening then testing for Down risk. Experts estimated that less than $2 \%$ of pregnant women in the US underwent amniocentesis for this indication as compared to 5-7\% in Western Europe (Greely, 2011). In the absence of an organized screening for Down risk women, especially those from lower socioeconomic strata, had lower chances to learn about health problems of their future child, and if applicable, to elect to terminate the pregnancy. This was seen as a problem by advocates of screening and a blessing in disguise by its opponents. (Vassy, 2006). Important differences in organization of screening for Down among Western European countries stem from differences in local health care cultures and organization of prenatal care (Crombag et al, 2014; Vassy et al, 2014). In France screening for Down risk was diffused from early 1990s on. In 2009 the French Health Ministry issued official recommendation for a first semester screening for Down. The screening is voluntary and women have to sign an informed consent forms. On the other hand refusals to undergo screening are relatively rare (Vassy, 2006; Dommergues et al., 2010 ). The UK implemented circa 2000 several pioneering programs for first semester screening; they were gradually extended in the following years (Williams et al, 2005; Thomas, 2017). The overall uptake of screening for Down syndrome in the UK is lower than in France, as is the (official) number of terminations of pregnancy for a fetal indication. On the other hand the French and the UK data are not entirely comparable since in the UK women can abort without providing a medical reason until 24 weeks of pregnancy, and in France only until 14 weeks (Vassy et al. 2014). Denmark has a very high acceptance rate of screening for Down; this is the case in Finland too. By contrast, 
in Norway screening for Down is offered only to women over 38 years and those known to have an increased risk of giving birth to a disabled child, and the uptake of screening for Down is relatively low. In Sweden and Island women receive a detailed information about screening for Down, but are not actively encouraged to undergo it. (Schwennsenn et al, 2010; Mescus, 2012). In Netherlands women were not encouraged to screen for Down risk and the test was not covered by the national health insurance, while Belgium adopted a screening model akin to the French one (Crombag et al, 2014; Roseman 2016).

Risk of Down syndrome, and, by extension, of other fetal chromosomal anomalies, is a situated entity which comes into being as a result of complex interactions between legal, economic, material, sociocultural and professional considerations. Differences in the implementation and diffusion of tests destined to uncover the presence of fetuses with chromosomal anomalies produced, to follow the anthropologist Margaret Lock, "local fetal biologies.”(Lock, 2001). Debates on the diffusion and regulation of "screening for Down" often reflect the persisting uneasiness with a diagnostic approach which, although often presented as aiming to help parents to prepare for the birth of a "special needs" child, in practice often leads to a choice to terminate a pregnancy. In this regard. prenatal diagnosis of a genetic condition is radically different from other genetic tests. Debates on such texts included considerations of their clinical utility (Parthasarathy, 2007) The highly emotional tonality of debates on abortion for non-lethal fetal indications, entangled from the 1980s on with discussions on disability rights and for some the (presumed) eugenic aspiration to exterminate imperfect humans, made very difficult an evaluation of "clinical utility" of such tests. 
iii. Marketing of an industry-driven innovation

Many $20^{\text {th }}$ century biomedical innovations were driven by pharmaceutical, biotechnology or medical instruments industry (e.g., Hobby,1985; Blume, 1992, Marks, 2015). NIPT was however, different. Initial attempts to develop approaches which studied fetal hereditary material using cells or free nucleic acids in maternal serum were made in fundamental research laboratories, but from very early stages of development of this diagnostic technology, all the clinical research on this subject was industrydriven, and results were first published on company's websites.

In the late 1970s scientists first attempted to isolate fetal cells present in the maternal circulation. (Herzenberg et al. 1979) They obtained partial successes in the research laboratory, but failed to develop clinical applications of this method (Bianchi, 2010). The breakthrough came with the finding an important amount of circulating free fetal DNA (cfDNA) in the blood of pregnant women (Lo et al, 1997, Bianchi, 1998). In the 2000s, the increasing power of computers led to the development of a new genomic technology, next generation sequencing, which made possible the development of cfDNA-based tests for the detection of Down syndrome. In 2008, Denis Lo's group in Hong Kong, and, independently, Stephen Quake's group at Stanford university, patented cfDNA-based tests for Down. Lo's group was at that point collaborating with the biotechnology firm Sequenom, and Quake's group with the firm Verinata. All the stages of development and testing of diagnostic tests were conducted by the industry and were covered by industrial secret. The cfDNA based tests, presented as a radical 
revolution in prenatal diagnosis, entered an era of commercial exploitation, patent wars and an intense competition on markets.

The new technology, named at first non -invasive prenatal diagnosis (NIPD), and then non-invasive prenatal testing ( NIPT), was initially conceived as a replacement for the existing methods of screening for Down syndrome, above all serum tests (ultrasound diagnosis detects also structural anomalies of the fetus). In 2012 clinical trials validated NPIT's capacity to detect trisomy 21, 13 and 18 (Palomaki et al, 2012). In that year, four cfDNA based tests: Seqenoms's Materni T21Plus, Verinata's Verifi, Ariosa's Harmony, and Nantera's Panorama obtained marketing permit in the US. Their prices varied from $\$ 800$ to 1400 ( in 2018 the price-range for NIPT, was reported to be $\$ 500-\$ 2100$.NIPT continues to be more expensive than alternative methods of testing for Down risk) (Allyse and Wick, 2018). In 2013, Sequenom's Materni T21 Plus, Verinata's Verify, and Nantera's Panorama included also testing for an abnormal number of sex chromosomes and fetal sex (Agrawal et al, 2013). Women could elect to receive an additional information on sex chromosomes anomalies, or opt out. Unsurprisingly the majority did not chose the latter option, in spite of the fact that screening for sex chromosome aneuploidies is less reliable than for autosomal aneuploidies (Allyse and Wick, 2018; Ramdanev et al, 2018).

At first NIPT was proposed only to high-risk women. NIPT producers weren however, very interested in proving that the test was efficient in low-risk women too, a much larger market for their product. First studies of the use of NIPT by low-risk women, published in 2014, indicated that NIPT was indeed more efficient as a "'first intention" screen for Down. Half of the "low risk" women who received a "positive" NIPT result for Down, this result was was confirmed by amniocentesis. By contrast, 
only about $4 \%$ of women classified as being at higher than average risk of carrying a Down syndrome on the basis of a combination of serum and ultrasound markers fetus,then underwent amniocentesis, learned that the fetus has indeed trisomy 21 (Greene, 2014). This result was, however, obtained in relatively small sample, was not seen as entirely reliable, and some experts sustained that a first intention screening with a combination of serum and ultrasound markers made possible the detection of a wider range of fetal anomalies. Guidelines issued in 2015 by the American College of Obstetrics and Gynecology (ACOG) did not validate the use of NIPT in low risk women. (ACOG, 2015; Benn et al, 2015). In spite of the lack of official endorsement, the use of NIPT as a "first screen" rapidly dominated the diffusion of this test in the US. Such an use of NIPT might have been favored by gynecologists' apprehension of legal pursuits. In 2007, ACOG defined the offering of screening for Down (including an amniocentesis, if a woman wishes it) as a standard of care for all the pregnant women, independently of their risk. This statement that could have been re-interpreted as an obligation, for a gynecologist, to offer all his patients the state of art screening method-NIPT -- as an alternative to other forms of screening.

One of the consequences of the rapid diffusion of NIPT in the US was that many women who looked above all for reassurance that the fetus does not have Down syndrome but accepted the additional testing for sex chromosome aneuploidy learned about a high probability that the fetus has an anomaly they might have had never heard about. The problem of unanticipated findings of NIPT was amplified in 2014 when several companies proposed "extended" NIPT that tested for additional chromosomal anomalies (mostly deletions), linked with inborn impairment, some of which, such as DiGeorge syndrome (22q11.2 del) have a variable expression (Hayden, 2014). The 
"extended" or "complete" NIPT was offered at somewhat higher price than the "basic" NIPT which frequently includes in the US testing for sex chromosome aneuploidies. The "extended" NIPT, like its basic version, was presented as aiming at preparing parents for birth of a "special need" child. (Löwy, 2017).

NIPT does not provide a definitive diagnosis, and the results, its users are told, have to confirmed by amniocentesis or CVS. Not all the women accept this rule. In the US, $6 \%$ of women whose NIPT results indicate a high probability of fetal chromosomal anomaly elected abortion without a further verification, while an important proportion of those diagnosed with a high probability of sex chromosome aneuploidy elected not perform additional tests (Dar et al, 2014; Ramdanev et al, 2018). It is probable that the proportion of women who decide to terminate the pregnancy on the basis of NIPT results alone is higher in countries in which abortion is illegal. In these countries it is easier for a woman to perform an illegal abortion early in pregnancy using abortive drugs, than to confirm NIPT results with amniocentesis and take the risk a later, more complicated abortion, and for some, of a denunciation as well. It is also possible that not every woman who learns about an increased probability of impairment of the future child wishes to pursue testing and to confirm the initial result; some women may perceive ambivalence as a blessing.

In Western Europe, national health systems which gradually decided to introduce NIPT, elected a different trajectory. They follow the recommendations of the shared position document on the uses of NIPT, issued in 2015 by the European Society of Human Genetics and the American Society of Human Genetics. This document recommended to limit (as for now) the use NIPT to search for three autosomal aneuploidies: trisomy 21 (Down syndrome) trisomy 13 (Patau syndrome) and trisomy 
18 (Edwards syndrome),; the two latter conditions are linked with very high rates of prenatal and postnatal mortality . NIPT is proposed only to women defined as being at "high risk" of chromosomal anomalies. Those with positive results of NIPT are then offered an invasive test. The use of NITP as "second level screen" markedly increases the odds that an invasive test will confirm the presence of a trisomy. (Dondorp et al., 2015), At the same time, some countries, such as France, enlarged the definition of "high risk of Down."

In countries with pre-existing screening for Down, NIPT is presented as technical improvement of such screening, not a conceptual revolution. A possible replacement of serum tests for a risk of Down with the use of NITP as a first screen for trisomy 21,13 and 18 is not expected either to produce dramatic change in the preexisting patterns of prenatal screening. Affluent users in Europe, including "low risk" women, can purchase privately either a "basic" NIPT test which detects only trisomy 21,13 and 18, or an "extended" one which includes testing for sex chromosomes and chromosomal deletions. It is however, reasonable to assume that only small fraction of women in countries with a national health insurance purchase NIPT on free market.

The introduction of NIPT into national health systems which had already implemented screening for Down is expected to produce an important decrease in number of amniocenteses and spare women the pain and stress linked with this test. (Chitty and Kroese, 2015), This technology was also expected to reduce the number of spontaneous miscarriages linked with higher number invasive tests. A prospective French clinical trial failed, however, to detect the latter effect (Malan et al, 2018). Introduction of NIPT is also predicted to lead to a moderate increase in the detection of major aneuploidies, and, since trisomy 13 and 18 often lead to newborn deaths and 
many women elect termination of pregnancy for these conditions, also a modest decrease in perinatal mortality. The introduction of cfDNA based tests in countries with a pre-existing screening for Down produced thus (as for now) relatively modest changes in prenatal diagnosis rather than the predicted revolution (Zeng et al, 2016; Lewis et al, 2017).

iii) Discussing NIPT before and after the marketing of this diagnostic technology.

In 2007, when commercial tests based on cfDNA were expected to reach the market soon, an US jurist, Carolyn Jacobs Chachkin produced a detailed and thoughtful review of the potential advantages and pitfalls of the new diagnostic technology. Chackin assumed that cfDNA based tests will provide a definitive diagnosis of fetal anomalies. She also assumed that cfDNA based tests will be much cheaper than the existing diagnostic approaches, (she estimated that their price will be between $\$ 100$ \$200). Chachkin predicted therefore that these tests will rapidly be integrated into the routine prenatal care, dramatically increasing the number of US women who will use prenatal genetic testing. Such testing, she anticipated, will became as popular as prenatal ultrasound, will be rapidly transformed into a standard of care, and will be fully covered by insurance companies. A probable consequence will be a significant increase in abortions for fetal anomalies and a significant decrease in the proportion of babies born with genetic disorders. The introduction of cfDNA based diagnosis may therefore open the way to pressures to abort impaired fetuses, a subtle form of eugenics. Overall, 
however, Chacking viewed the arrival of the new tests as a very positive development (Chachkin, 2007).

Other US scholars shared Chackin's assumptions and concerns. They too assumed that the new technology, named in the meantime noninvasive prenatal diagnosis or NIPD, will rapidly became accurate and inexpensive, and will detect a great number of hereditary / genetic disorders. They viewed a large scale diffusion of commercially produced NIPD as an ineluctable development, and pointed to its potential advantages: enlargement if parental choices and (probably) a reduction of prevalence of severe hereditary disorders, but also its dangers; flooding of future parents with confusing and stress-generating information, a push toward abortion for moderate and minor fetal impairments, and greater stigmatization and social exclusion of those living with disabilities. (Benn and Chapman, 2009; Benn and Chapman, 2010; Greely and King, 2010; Greely 2011; Proffitt, 2013). These risks may be amplified by a direct to consumer (DTC) diffusion of NIPD.( Haymon, 2011).

UK experts who evaluated NIPD's future were more prudent. They predicted that the new technology will be rapidly employed to detect autosomal aneuploidies, but were less certain that it will rapidly move beyond the diagnosis this indication. They were also less sure that NIPD will swiftly replace testing for serum markers of fetal anomalies. Nevertheless they too assumed that cfDNA based tests for a wide range of genetic conditions will reach the market in a relatively near future, a development that will amplify the ethical dilemmas linked with selective abortion for fetal indication. Such dilemmas, they added, may be magnified by the fact that NIPT is developed exclusively by private companies and destined to be sold on the market (Hall et al., 2009). Discussions about the future of cfDNA based tests did not evoke "clinical 
utility," since it is difficult to frame the potential prevention of birth of an impaired child in "utility" terms, but they did discussed the potential social harm of these tests.. They also did not debates explicitly the possibility of prohibition of specific uses of NIPT, or of their marketing directly to consumers.

Scholars who participated in the early debates on NIPD did not predict that results of cfDNA-based tests will be indicative only and will have to be confirmed by an invasive test; that the marketing of cfDNA-based tests which will "read" the entire fetal genome will not follow rapidly the diffusion of tests for selected chromosomal anomalies; or the relatively high price of this diagnostic technology. They also did not discuss the possibility that the inclusion of NIPT within the framework of an already existing screening programs for "Down risk" will follow a different path than the diffusion of this test on a free market. An additional, non-anticipated, problem was the that in some cases a cfDNA based test displayes an unsuspected maternal pathology, usually a malignancy (Bianchi et al., 2015).

Once available on the market, NIPT stimulated debates about a different questions. Some scholars continued to evoke the potential consequences of cfDNA based tests that will examine the entire fetal genome (e.g. Ravitsky, 2015; Shakespeare, 2015), but discussions on the new diagnostic technology were mainly focused the already existing screening for major chromosomal anomalies. Many questions evoked in these debates, such as the evaluation of specify and reliability of the test, its cost/ efficacy, its reimbursement by national health insurance (when applicable), or the obtention of an informed consent of test users were already present in debatres about the introduction of serum markers for "Down risk." They also shared with earlier discussions about screening for Down a tendency to escheve the thorny issue of a 
selective abortion for fetal indication, and an implicit consensus that professionals will be the main gate keepers of access to tests, while such access will be also indirectly regulated through policies of health insurers.

Other potentially problematic aspects of NIPT were seen as specific for this technology. Among them, the exclusive development and diffusions of NIPT by commercial firms and the greater risk of integration of this test into routine surveillance of pregnancy without adequate counseling.The development of genetic counseling was closely related to the introduction of amniocentesis, because of risks linked with invasive testing (Stern, 2012). NIPT is risk-free, increasing the probability that women will take this "simple blood test" without being adequately informed what this test is , and what is the precise meaning of a "positive" result. Women who undergo NIPT, but also some health care providers, may confuse NIPT's high specificity and sensitivity (an absolute variable) with the test's positive predictive value, that is, the probability that a woman who tests positive for a specific fetal anomaly indeed carries a fetus with this anomaly, a variable that depends on the frequency of a given anomaly in the tested population (a relative variable, and the one that matters for the tested woman). (Shakespeare, 2015; Lewis, 2017, Ravitsky et al., 2018).

iv. NIPT in "intermediary economies:” Brazil and China.

Diagnostic technologies based on the study of cfDNA in maternal circulation rapidly reached Brazil, where they took a specific form. From the early 2000 on Brazilian laboratories developed fetal DNA based tests for the detection of fetal sex. Sex determination was one of the first uses of cfDNA-based tests. Pregnant woman do 
not have Y chromosome markers, and presence of such markers in their blood indicated therefore that the fetus is male. Testing for fetal sex is possible from the $6^{\text {th }}-7^{\text {th }}$ week of pregnancy, and this test is much simpler and cheaper than a cfDNA based test that detects an abnormal number of fetal chromosomes. There are medical reasons to detect fetal sex early in pregnancy. For example, when a woman is at risk to give birth a child with congenital adrenal hyperplasia $(\mathrm{CAH})$, it may be important (at least according to some experts) to know rapidly whether the fetus is female and if that is the case, to propose her a treatment with the steroid dexamethasone to attenuate the "virilization" of a female fetus. If the fetus is male, treatment with dexamethasone is not necessary and may be harmful. There are also numerous non-medical reasons why a women may want to know rapidly the fetus's sex, from curiosity to a wish to abort a fetus of a "wrong" sex.

In early $21^{\text {st }}$ century US companies such as Baby Sex Mentor ${ }^{\mathrm{TM}}$ and Pink or Blue® marketed by Acu-gen Biolab Inc. and Consumer GeneticsInc, proposed to pregnant women DTC tests for fetal sex using blood from a finger prick tests. The price of such test was approximately $\$ 250$. At that time, experts were critical of these test, mainly because firms that proposed them were not required to maintain high standards of reliability. They also mentioned the risk of prenatal sex selection, especially in societies which favor male children, and of marketing of DTC cfDNA-based paternity tests. (Bianchi 2006; Hall et al, 2009). Many countries impose a strict regulation of paternity tests, but such regulation usually defines the acceptability of such tests by courts. It does not cover the possibility that a pregnant woman will attempt to verify who the father of her future child is - usually without the permission of the potential father(s) - and may terminate the pregnancy if, e.g., the father is not her long-term 
partner, is somebody she cannot accept as a parent of her child, or, in a darker version, is not the man she plans to sue for paternity benefits. With the commercialization of "basic" NIPT which included an option to reveal the fetus's sex, tests that detected only fetal sex became less visible, at least in industrialized countries. They remained, however, popular in Brazil.

In Brazil locally produced tests that reveal the "baby's sex" early in pregnancy continue to be proposed to middle class women, sometimes as a part of a "package" of prenatal care in a private clinics. The tests are relatively inexpensive: in 2015 their price was around $300-400$ reals, that is, approximately $\$ 80-\$ 100$, an acceptable sum for a middle class woman. Street corner obstetrical ultrasound clinics can reveal the fetal sex for a much lower price ( in some cases as little as 20-30 reals), but this is possible only in the second trimester of pregnancy, typically at 20-22 weeks. The widespread use of tests that predict the fetus's sex/gender early in pregnancy is linked to the cultural importance of this knowledge in Brazil. Once the fetus's sex is known, the future child, becomes "our baby", is given a name, and middle class families start shopping for gender-appropriate clothes and accessories. (Chazan, 2008). In the US too, reveling of the fetal sex is a culturally significant event, celebrated in the increasingly popular "sex revealing" parties (Vincent, 2018). The detection of fetal sex as a key milestone in making the future child "real" is not an universal trait. In Israel pregnancy is perceived as fraught with danger and Israeli -Jewish families do not celebrate baby showers or organize sex-revealing parties; some even refrain from purchasing baby's clothes and furniture until the child's birth. On the other hand, a high level of anxiety about of pregnancy's outcomes encourages the use of a wide range of prenatal tests (Ivry, 2009; Zielinska and Löwy, 2017). 
Brazilian families do not have a strong preference for male children, and Brazilian gynecologists affirm that the detection of fetal sex has no incidence on rates of termination of pregnancy. Detection of chromosomal anomalies of the fetus has a very different meaning. Since abortion for a fetal indication is illegal in Brazil with the sole exceptions of anencephaly, the Brazilian national health system do not propose prenatal diagnosis of fetal impairments (Diniz and Medeiros, 2010). On the other hand, only poor Brazilian women use maternity services provided by the state. Middle and upper class women use the services of private gynecologists who, especially if they work in upper-end maternity clinics, tend to prescribe numerous diagnostic tests. Such tests, and the use of sophisticated medical imagery equipment, stand for a cutting-edge, high quality medicine. Middle and upper class pregnant women frequently undergo tests for "Down risk" at the end of first trimester of pregnancy. If these tests (serum markers and nuchal translucency) uncover a higher than average risk of fetal anomaly, the woman usually undergoes amniocentesis, and if the result is "positive," she can elect an illegal but safe -abortion. The low number of children with inborn defects born in private hospitals and clinics indirectly indicates that affluent Brazilian women undergo selective termination of pregnancy (Horovitz at al., 2013).

In 2013, two US producers of NIPT, Ariosa, the producer of Harmony test and Natera, the producer of Panorama test signed agreements with Brazilian laboratories to offer NIPT to Brazilian women. Regulation was not an issue, since the tests were offered only in the very weakly regulated private health sector. Official presentations of these test stressed that NIPT will help families to be better prepared to birth of a special needs child. Laboratories that offer NIPT in Brazil took into account the fact that in the average age of childbirth in Brazil is lower than in industrialized countries. Brazilian 
publicity of the Panorama test explains thus that a "conventional" NIPT detects only trisomy 21, 13 and 18, while a "complete" test, detects also several chromosomal deletions. Down syndrome, the leaflet adds, is more frequent in older women, while the risk of microdeletions does not depend on woman's age. Pregnant women under thirty are therefore at a higher risk to have a child with a microdeletion than with Down syndrome, and are advised to have a "complete" test.

In 2013, when NIPT was introduced into Brazil, many specialists thought that this test will have a limited diffusion only, mainly because the test's price, at that time approximately $\$ 1200$, was approximately four times higher than screening for Down risk through a combination of serum tests and ultrasound. However, one year later NIPT became firmly integrated into prenatal testing in the Brazilian private health sector. The test's cost did not discourage affluent women who wanted to be reassured rapidly "the baby is all right." The majority of Brazilian users of NIPT are "low risk" women. Ultrasound experts who work in upper end gynecological clinics attested that often patients arrive for their 12 weeks ultrasound examination with their NITP results. Many services provided by the high-end maternity clinics are not reimbursed by Brazilian private health insurance, and women who chose such a clinic are willing to pay from their pocket for its services. The price of NIPT is not very elevated when compared to their other pregnancy-related health expenses, for example a consultation with a wellknown ultrasound expert. In a sub-culture that puts to the fore the consumerist aspect of health care and maternity, the purchase of an expensive cfDNA-based test may be seen as a less frivolous version of a purchase of a costly baby pram.

The trajectory of cfDNA based tests in another intermediary economy, China, is at the exact opposite of the Brazilian free market approach. Chinese NITP was a local 
product. Between 2011 and 2014 several Chinese private companies, such as Beijing Genomic Institute (BGI) and Berry Genomics, active also on European market, marketed NIPT for Down syndrome and other aneuploidies: testing for fetal sex is prohibited by the Chinese law. Chinese cfDNA based tests were less expensive than Western ones, but their price (2000-3000 RMB, about $\$ 250$ - 350 in 2016) made them too expensive for lower-class users. The Chinese NIPT tests circulated freely on the internal market for about three years, but in February 2014, the Chinese Food and Drug Administration and the National Health and Family Planning Commission announced that the diffusion of all the prenatal genetic tests, including NIPT, was suspended until the implementation of a new regulation. The regulatory instances justified this decision by the claim that the commercial market for genetic testing was chaotic, the quality of the tests was highly variable, and there was no guarantee that the companies that produced genetic tests could deliver what they promised.. In June 2014 the Chinese regulatory agencies accorded a conditional marketing permits to a small number of cfDNA based tests produced by well-known manufacturers. These tests are available on the private market. In addition, however, several Chinese provinces incorporated NIPT for selected indications into state- sponsored parental care, and proposed partial reimbursement of the test's costs (Zeng et al, 2016; Jin et al, 2017). The Chinese approach, in which NIPT is assimilated to other genetic tests and is strictly regulated by the state contrasts not only with the Brazilian total "laissez faire," but also with the attitude of Western European countries which do not prohibit a private purchase of cfDNA based tests, prescribed by the woman's doctor.

NIPT (including in China) was introduced by biotechnology companies that prioritized private or semi-private markets and tests that detect major chromosomal 
anomalies(Chandrasekharan et al, 2014; Minear et al, 2015). One could imagine, however, a different configuration, in which this diagnostic technology was supported by public or charitable funding, and harnessed to the goal of improvement of prenatal care in lower- income countries. In such countries, women, especially those who live outside urban centers, have a limited access to advanced diagnostic approaches such as high quality obstetrical ultrasound and amniocentesis. NIPT can partly compensate for shortage of qualified gynecologists and ultrasound experts because blood samples of pregnant women can be collected by community health workers and and sent to a central laboratory. As a result, more women receive information about fetal anomalies and - if they live in a society in which abortion is not criminalized—can make an informed choice about the future of their pregnancy (Allyse et al., 2015). One can also imagine cfDNA based tests tailored to the needs of populations outside North America and Western Europe. Such tests can be calibrated for detection of locally important diseases such as thalassemia or sickle cell anemia (Mozersky et al, 2018). The latter possibility is, however, purely theoretical. Technologies incorporate in their design the values that guided their development. There is no way of knowing how cfDNA-based diagnostic approach shaped by a different sets of values and considerations might have looked, or how it could have been distributed and regulated.

v. Final remarks: global markets, situated uses.

The short history of NIPT displays the complicated relationships between the global and the local in health care. Social scientists increasingly recognize the need to 
pay attention to the context that shape the production, diffusion and regulation of new diagnostic and therapeutic approaches, and acknowledge that one size does not fit all. Diagnostic innovations -like other technological innovations-- came into being in a full world. They compete with already existing technologies and are shaped by institutional and organizational variables, economic and political considerations, local medical cultures, and legal and regulatory frameworks. The regulation of marketing and use of NIPT followed the general rules that govern the marketing of akin diagnostic tests. such as those which detect "serum markers" for Down. The regulatory instances examined above all conformity of this test to the producers claims about its efficacy and reliability. In practice, the use of this biomedical innovation were molded by the ways it became accessible to pregnant women, or, in China, by those that govern the use of all the genetic tests. They reflected national and regional differences in structure of health insurance, cultural variables" writ large, and, in Western Europe, the history of implementation of a nationwide screening for "Down risk."

A disclaimer of the 2009 PHG foundation report on the ethical legal and social issues arising from cell-free nucleic acid technologies affirmed that ,"the field of noninvasive prenatal diagnosis is extremely dynamic and technology is developing very rapidly; this report is accurate as of 7th January 2009." (Hull et al, 2009). The same disclaimer is valid for this text too; it provides a - surely incomplete - overview of uses of NIPT in summer 2018. The observation that many of the publicatins that discussed cfDNA based tests before their marketing became rapidly obsolete, is an invitation to be modest. It is not possible to know whether NIPT will continue to be employed in its present-time form, will undergo important modifications, or will be rapidly replaced byvery different diagnostic approach, and whether it will be submitted to more formal 
regulation, or its use will continue to be shaped by decisions of doctors that prescribe this test and women's access to this diagnostic technology. It is, however, probably not too risky to assume that whatever the future of NIPT will be, it will continue to be strongly affected by situated variables. It is also reasonably to assume that while it is possible to collect at least partial information on cfDNA-based tests prescribed by health professionals and employed in the framework of medical supervision of pregnancy, other, less visible, and in some countries illegal, DTC uses of this diagnostic technology, such as sex selection, may exist as well. The central role of the industry in the development of this diagnostic innovation, strong links between NIPT and the highly contentious topic of selective abortion, and the weak regulation of marketing of tests, may favor the existence of gray zones of cfDNA-based prenatal testing .

\section{Bibliography.}

Agarwal, A., Sayres, L., Cho, M.K., Cook-Deegan; R., and Chandrasekharan, S. (2013). Commercial landscape of noninvasive prenatal testing in the United States. Prenatal Diagnosis 33: 521-531.

Allyse M., Minear, M.A., Berson, E., Sridhar S., Rote M., Hung A, and Chandrasekharan S. (2015). Non-invasive prenatal testing: a review of international implementation and challenges. International Journal of Women's Health, 7:113-126. 
Allyse, M., and Wick,M., (2018). Noninvasive prenatal genetic screening using cell-free DNA. JAMA, 320(6): 591-592.

American College of Obstetrics and Gynecology (ACOG). Committee Opinion No. 640: Cell-Free DNA Screening For Fetal Aneuploidy. Obstetrics and Gynecology, ;126(3):e31-7. doi: 10.1097/AOG.0000000000001051.

Benn P and Chapman A. (2009). Practical and ethical considerations of noninvasive prenatal diagnosis. JAMA, 301(20): 2154-2156.

Benn P and Chapman A. (2010) . Ethical challenges in providing noninvasive prenatal diagnosis. Current Opinion in Obstetrics and Gynecology, 22:128-134.

Benn, P., Curnow, K, , Chapman, S., Michalopoulos, S.N., Hornberger, J. and Rabinowitz, M., (2015). An economic analysis of cell-free DNA non-invasive prenatal testing in the US general pregnancy population. PLoS One 10(7): e0132313. doi:10.1371/journal.pone.0132313.

Bianchi, D. (1998).Fetal DNA in maternal plasma: the plot thickens and the placental barrier thins. American Journal of Human Genetics 62: 763-64

Bianchi, D. (2006). At-home fetal DNA gender testing: caveat emptor. Obsterics and Gynecology, 107(2): 216-218. 
Bianchi, B. (2010). From Michael to microarrays: 30 years of studying fetal cells and nucleic acids in maternal blood. Prenatal Diagnosis 30: 622-623.

Bianchi, D., Chudova, D., Sehnert, A. J., et al. (2015). Non invasive prenatal testing and incidental detection of occult maternal malignancies. JAMA, 14(2):162-169.

Birko, S., Lemoine, M.E., Nguyen, M.T., and Ravitsky V. (2018). Moving towards routine non-invasive prenatal testing (NIPT). Challenges to women's autonomy. OBM Genetics, 2(2): doi:10.21926/obm.genet.1802018.

Boyd P., and Game, E. (2011). Special Report, Prenatal Screening Policies in Europe, 2010. Ulster, Eurocat Central Registry.

Blume, S. (1992). Insight and Industry.: On the Dynamics of Technological Change in Medicine. MIT Press.

Chachkin, C.J. (2007). What potent blood: non-invasive prenatal genetic diagnosis and the transformation of modern prenatal care. American Journal of Law and Medicine, 33(1): 9-53.

Chandrasekharan, S., Minear, M.A., Hung, A. and Allyse, M.(2014). Noninvasive prenatal testing goes global. Science Translation Medicine, 6, $231 \mathrm{fs} 15$ (2014). 
Chazan -Krakowsky, L. 2008. E ta gravida mesmoé E ele e lindo! A construcao de "verdades" na ultra-sonografia obstetrica. Manguinhos, 15: 99-116.

Chitty, L., and Kroese, M. (2015). "Editorial: Realising the promise of noninvasive prenatal testing," British Medical Journal;350: h1792

Crombag, N., Vellinga,Y., Kluijfhout, S., et al. (2014).Explaining variation in Down's syndrome screening uptake: comparing the Netherlands with England and Denmark using documentary analysis and expert stakeholder interviews? BMC Health Services Research 14 : 437. doi: 10.1186/1472-6963-14-437.

Dar, P.,. Curnow, K.J. Gross, S. et. al.,(2014). Clinical experience and followup with large scale single-nucleotide polymorphism- based noninvasive prenatal aneuploidy testing," American Journal of Obstetetrics and Gynecology 211: 527.e1527.e17. doi: 10.1016/j.ajog.2014.08.006

De Jong, A., Dondorp, W.J., Frints, S., de Die-Smulders , C. and de Wert, G. (2011). Advances in prenatal screening: the ethical dimension. Nature Reviews, Genetics, 12: 657-663.

Diniz D, Medeiros M. Abortion in Brazil: a household survey using the ballot box technique. Cien Saude Colet 2010;15:959-66. 
Dommergues, M., Mandelbrot,L., Mahieu-Caputo, D. , et al., 'Termination of pregnancy following prenatal diagnosis in France: how severe are the foetal anomalies?', Prenatal Diagnosis 30 (2010): 531-39.

Dondorp, W., de Wert, G., Bombard, Y et al. (2015). Non-invasive prenatal testing for aneuploidy and beyond: challenges of responsible innovation in prenatal screening . European Journal of Human Genetics, 23 : 1438-1450.

Hayden, E.C. (2014) . Prenatal-screening companies expand scope of DNA tests, but the increasingly accurate analyses carry the ethical dilemma of uncertain outcomes. Nature, 507: 19.

Herzenberg, L., Bianchi, D., Schroder, J., Cann H., and Iverson, M. (1979). Fetal cells in the blood of pregnant women: detection and enrichment by fluorescenceactivated cell sorting. Proceeding of the National Academy of Sciences (USA) 76: 14531455.

Horovitz, D., Ferraz, V.A., Dain S., and Marques-de-Faria, A. (2013). Genetic services and testing in Brazil. Journal of Community Genetics, 4: 355-375.

Greely, H. 2011, Get ready for the flood of fetal gene screening," Nature 469: 289-91. 
Greely H and King, J. 2010. The coming revolution in prenatal genetic testing," AAA Professsional Ethics Report 23: 1-8.

Greene,M. (2014) "Screening for trisomies in circulating DNA," New England Journal of Medicine 370: 874-875.

Hall, A., Bostanci, A., and John, S., (2009). Ethical, legal and social issues arising from cell-free fetal DNA technologies. Appendix 3 to the repport, Cell-free fetal nucleic acids for non-invasive prenatal diagnosis. Foundation for Genomics and Population Health,UK. (PHG), 2009.

Haymon, L. (2011). Non-Invasive Prenatal Genetic Diagnosis (NIPD). Council for Responsible Genetics (US), 2011.

Hobby, G. (1985) Penicillin: Meeting the Challenge, Yale University Press.

Horovitz, D., de Faria Ferraz, V., S Dain S., and Marques-de-Faria, A.P. (2013). Genetic services and testing in Brazil, Journal of Community Genetics, 4: 355-375.

Ivry, T. (2009). Ultrasonic picture show and the politics of threatened life . Medical Anthropology Quaterly, 23(3): 189-211. 
Jin, J., , Junwen Yang, J., Chen, Y.,and Huang,J. (2017). Systematic review and meta-analysis of non-invasive prenatal DNA testing for trisomy 21: implications for implementation in China. Prental Diagnosis, $37: 864-873$.

Lewis, C., Hill, M., and Chitty, L. (2017). Offering non-invasive prenatal testing as part of routine clinical service. Can high levels of informed choice be maintained? Prenatal Diagnosis. 37: 1130-1137.

Lo, D.Y., Corbetta, N.,Chamberlain, P., Rai,V., Sargent, I., Redman, C., and Wainscoat, J. (1997). Presence of fetal DNA in maternal plasma and serum. The Lancet, 350: 485-87.

Lock, M. (2001). The tempering of medical anthropology: troubling natural categories," Medical Anthropology Quarterly 15: 478-92.

Löwy, I. 2014. Prenatal diagnosis : The rresistible rise of the 'visible fœtus.' Studies in History and Philosophy of Biological and Biomedical Sciences, 47: 154-162.

Löwy, I. 2017. Imperfect Pregnancies: A History of Birth Defects and Prenatal Diagnosis. Johns Hopkins University Press.

Malan, V., Bussieres, L., Winer, N., et al., (2018). Effect of cell-free DNA screening vs direct invasive diagnosis on miscarriage rates in women with pregnancies at high risk of trisomy 21: a randomized clinical trial. JAMA, 320 (6): 557-565. 
Marks, L. (2015). The Lock and Key of Medicine: Monoclonal Antibodies and the Tranformation of Health Care. Yale University Press.

Meskus, M. (2012). Governing risk through informed choice: prenatal testing in welfarist maternity care," in Contested Categories. Life Sciences in Society, Susanne Bauer and Ayo Wahlberg, eds. Farnham and Burlington: Ashgate, 2012, 49-68.

Minear, M.A., Lewis, C., Pradhan, S., and Chandrasekharan, S. (2015). Global perspectives on clinical adoption of NIPT. Prenatal Diagnosis, 35(10): 959-967.

Mozersky J, Ravitsky V., Rapp, R., Chandrasekharan, S., and Allyse, M. (2017). Toward an ethically sensitive implementation of noninvasive prenatal screening in the global context. Hasting Center Report, March-April, 2017: 41-49.

Palomaki, G.E., Deciu ,C., Kloza E.M., et al. (2012). DNA sequencing of maternal plasma reliably identifies trisomy 18 and trisomy 13 as well as Down syndrome: an international collaborative study. Genetics in Medicine 14: 296-305.

Parthasarathy, S. (2007). Building Genetic Medicine: Breast Cancer, Technology, and the Comparative Politics of Health Care. Cambridge, MA: The MIT Press. 
Proffitt, A. (2013). Advances in prenatal molecular diagnosis., Bio-IT- World October 7, 2013.

http://www.bio-itworld.com/2013/10/7/predicting-the-future-for-noninvasiveprenatal-testing.html

Ramdaney, A, Hoskovec, J., Harkenrider, J., Soto, E., and Murphy, L. (2018) Clinical experience with sex chromosomes aneuploidies detected by non-invasive prenatal testing (NIPT): accuracy and patient decision making. Prenatal Diagnosis, in press. doi: 10.1002/pd.5339.

Ravitsky, V. (2015). Background paper: Non-Invasive Prenatal Testing (NIPT). Identifying key clinical, ethical, social, legal and policy issues. Nuffield Council on Bioethics background paper, November 2015.

Rosman, S. (2016). Down syndrome screening information in midwifery practices in the Netherlands : Strategies to integrate biomedical information. Health, 20: 94-109.

Schwennesen, N., Nordahl Svendsen M., and Koch, L. (2010) Beyond informed choice: prenatal risk assessment, decision-making and trust," Clinical Ethics 5: 207-16; 
Shakespeare, T. (chair) (2017). Nuffield Council on Bioethics Working Group Report; Non Invasive Prenatal Testing: Ethical Issues. Nuffield Council on Bioethics 2017.

Stein, Z., Susser M.,and Guterman, A. (1973). Screening programme for Down Syndrome," The Lancet, 301, i: 305-310.

Stern A.M. (2012). Telling Genes: The Story of Genetic Counseling in America. Johns Hopinks University Press.

Stoll, .K. (2013). NPIS is not diagnostic_convincing our patients and convincing ourselves," The DNA Exchange Blog, July 11, 2013,

http://thednaexchange.com/2013/07/11/guest-post-nips-is-not-diagnosticconvincing-our-patients-and-convincing-ourselves/ (accessed 15 August, 2018).

Thomas, G. (2017).Down's Syndrome Screening and Reproductive Politics. London, Routledge.

Vassy, C. (2006). From a genetic innovation to mass health programmes: The diffusion of Down's Syndrome prenatal screening anddiagnostic techniques in France. Social Science \& Medicine, 63: 2041-2051. 
Vassy C., Rosman, S; and Rousseau, B. (2014). From policy making to service use. Down's syndrome antenatal screening in England, France and the Netherlands; Social Science and Medicine 106: 67-74

Vincent, M.R. (2018). People are going way over the top with their genderreveal parties these days. CNN, 8 June 2018.

https://www.cnn.com/2018/06/08/health/gender-reveal-parties-trnd/index.html

Williams, C., Sandall, J., Lewando-Hundt, G., Heyman, B., Spencer, K., and Grellier ,R. (2005). "Women as moral pioneers? Experiences of first trimester antenatal screening. Social Science \& Medicine 61 1983-92.

Zeng X., Zannoni, L., I. Löwy, I. and S. Camporesi, S. (2016). Localizing NIPT: Practices and meanings ofnon-invasive prenatal testing in China, Italy,Brazil and the UK. Ethics Medicine and Public Health , 2(3): 392-401.

Zieliniska, A. and Löwy, I.( 2017). The Golden Helix: Origins, ethnicity and preconception genetic screening in Israel. Biosocieties, DOI: 10.1057/s41292-0170070-3 
Ilana Lôwy is the only author of this text. 